\title{
Comprehensive Analysis of Coding and Non-coding RNA Transcriptomes Related to Hypoxic Adaptation in Tibetan Chickens
}

\section{Ying Zhang}

China Agricultural University

\section{Woyu Su}

China Agricultural University

\section{Bo Zhang}

China Agricultural University

Yao Ling

China Agricultural University

\section{Woo Kyun Kim}

China Agricultural University

Hao Zhang ( $\sim$ zhanghao827@163.com )

China Agricultural University https://orcid.org/0000-0002-7331-1550

\section{Research}

Keywords: non-coding RNA, ceRNA, transcriptome, Tibetan chicken, hypoxic adaptation

Posted Date: November 20th, 2020

DOI: https://doi.org/10.21203/rs.3.rs-111085/v1

License: (c) (i) This work is licensed under a Creative Commons Attribution 4.0 International License. Read Full License

Version of Record: A version of this preprint was published at Journal of Animal Science and Biotechnology on May 3rd, 2021. See the published version at https://doi.org/10.1186/s40104-021-00582-2. 


\section{Abstract}

Background: Tibetan chickens, a unique native breed in the Qinghai-Tibet Plateau of China, have a suite of adaptive features to tolerate the high-altitude hypoxic environment. Increasing evidence suggests that long noncoding RNAs (IncRNAs) and microRNAs (miRNAs) have roles in the hypoxic adaptation of high-altitude animals, although their exact involvement remains unclear.

Results: This study aimed to elucidate the global landscape of mRNAs, IncRNAs, and miRNAs using transcriptome sequencing in order to construct a regulatory network of competing endogenous RNAs (ceRNAs) and thus provide insights into the hypoxic adaptation of Tibetan chicken embryos. In total, 354 differentially expressed genes (DEGs), 389 differentially expressed IncRNAs (DELs), and 73 differentially expressed miRNAs (DEMs) were identified between Tibetan (TC) and Chahua chickens (CH). Functional analysis revealed that several important DEMs and their target DELs and DEGs are involved in angiogenesis (including blood vessel development and blood circulation) and energy metabolism (including glucose, carbohydrate, and lipid metabolism). The ceRNA network was then constructed with the predicted DEGs-DEMs-DELs interactions, which further revealed the regulatory roles of these differentially expressed RNAs during hypoxic adaptation of Tibetan chickens.

Conclusions: These transcriptomic data revealed several key candidate ceRNAs that may play high-priority roles in the hypoxic adaptation of Tibetan chickens by regulating angiogenesis and energy metabolism. These results provide insight into the molecular mechanisms of hypoxic adaptation regulatory networks from the perspective of coding and non-coding RNAs.

\section{Background}

MicroRNAs (miRNAs) are small non-coding RNA molecules that inhibit gene expression by binding to specific mRNAs. IncRNAs are another type of non-coding RNA that are approximately 200 nucleotides in length and regulate gene expression through a number of mechanisms. Both of these non-coding RNAs play different roles in various aspects of cellular function, including the regulation of hypoxia-related genes. Through their activity on target transcripts, some critical miRNAs regulate angiogenesis, the cell cycle, as well as lactate transport under hypoxic conditions [1-3]. HIF-1 and VEGF are regulated by miR-17-92, miR-20b, and miR-199a, which play roles in tumor development, cancer cell proliferation, and cardiac myocytes [4-6]. Various studies have shown that IncRNAs can directly bind to HIF-1 and activate its expression, in turn modulating hypoxic responses as done through suppression of cancer cell adaptation to hypoxia, which provides important insights into how tumor cells sense and adapt to hypoxic stress [7-9]. Although there have been many studies on genes involved in highaltitude adaptation in humans and animals, the regulatory mechanism of non-coding RNAs involved in hypoxic adaptation remains largely unknown.

Tibetan chickens, which have lived in Tibetan highlands and have undergone long-term natural selection, exhibit stable genetic adaptation to high-altitude environments characterized by high hatchability under hypoxic incubation when compared to lowland chickens $[10,11]$. This indicates that Tibetan chickens have special physiological and genetic mechanisms to adapt to extreme high-elevation environments ensuring their normal hatching, reproduction, and growth in plateau environments [12-14]. Previous studies using genomic, transcriptomic, and proteomic profiles have identified several functional genes related to hypoxic adaptation in Tibetan chickens [15-17]. However, the mechanisms involved in the non-coding RNA regulation of hypoxic adaptation are unclear. 
In this study, RNA sequencing (RNA-seq) was performed to explore the regulation of ncRNAs and candidate genes responsible for hypoxic adaptation traits in Tibetan chickens via comparison to Chahua chickens using embryos. These findings will help us further understand the molecular mechanism of adaptability to hypoxic conditions in Tibetan chickens from an ncRNA perspective.

\section{Methods}

\section{Sample collection and preparation}

The experiments and animal care protocol were approved by the animal welfare committee of the State Key Laboratory for Agro-Biotechnology of the China Agricultural University (approval number, XK257), and all methods were performed in accordance with the relevant guidelines and regulations.

We collected eggs from Tibetan chickens (TCs) and Chahua chickens (CHs) from the Experimental Station for Poultry Genetic Resources and Breeding, China Agricultural University (CAU). The eggs were incubated in a hypoxic incubator $\left(13 \% \pm 0.2 \% \mathrm{O}_{2}\right)$ and a normoxic incubator $\left(21 \% \pm 0.2 \% \mathrm{O}_{2}\right)$, and the temperature and humidity of the incubators were $37.8{ }^{\circ} \mathrm{C}$ and $60 \%$, respectively. Eighteen chorioallantoic membrane (CAM) samples from Tibetan $(n=9)$ and Chahua chickens $(n=9)$ under hypoxic conditions were collected from female embryos at day 11 of incubation, immediately frozen in liquid nitrogen, and stored at $-80^{\circ} \mathrm{C}$ for sequencing.

\section{RNA extraction, library construction, and sequencing}

Total RNA from eighteen CAM tissues of day 11 embryos was extracted using an RNA pure Tissue Kit (Tiangen Biochemical Technology Beijing Co., Ltd) according to the manufacturer's protocol. Six RNA-seq libraries (TC1, $\mathrm{TC} 2, \mathrm{TC} 3, \mathrm{CH} 1, \mathrm{CH} 2$, and $\mathrm{CH} 3$ ) were constructed, and each sample was mixed from three individuals of the same breed.

\section{Library preparation and sequencing of mRNA and IncRNA}

The Epicentre Ribo-ZeroTM kit was used to remove sample rRNA, and fragmentation buffer was added to randomly interrupt rRNA-depleted RNA. Using rRNA-depleted RNA as a template, the first cDNA strand was synthesized with random hexamers. Thereafter, buffer, dATP, dUTP, dCTP, dGTP, RNase H, and DNA polymerase I were added to synthesize the second cDNA strand. AMPure XP beads were used to purify cDNA. The doublestranded CDNA was repaired at the ends, adding poly-A and connecting the sequencing adapters. AMPure XP beads were then used for fragment size selection. The $U$ chain was degraded and the cDNA library was obtained by PCR enrichment. The library was sequenced on an Illumina HiSeq platform and 150 paired-end reads were generated.

\section{Library preparation and sequencing for sRNA}

After the sample was qualified, a linker was added to the RNA, which was reverse transcribed to synthesize cDNA, followed by PCR amplification. Gel separation technology was employed to screen the target fragment, and the fragment recovered by gel cutting was the small RNA library. The library was sequenced on an Illumina HiSeq platform, and 50 single-end reads were generated.

\section{mRNA and IncRNA data analysis}


Quality control was performed using in-house Perl scripts. Raw reads were filtered by removing reads containing adapters, poly-N, and low-quality reads, in order to obtain clean reads. The Q20, Q30, and GC content of the clean data were calculated. Clean reads were aligned to the chicken reference genome Gallus-gallus-6.0 (GRCg6a96.Gallus-gallus.GRCg6a-96.genome.fa) using the HISAT2 software [18]. LncRNA prediction was performed through basic screening and coding potential screening. The basic screening included: (1) Selecting the class-code of transcripts as "i", "x", "u", "o", "e" [19]; (2) Selecting transcripts with length $\geq 200$ bp and exon number $\geq 2$ [20]; (3) Selecting transcripts with FPKM $\geq 0.1$ [20]; and using four tools to further screen the selected candidate IncRNA in order to predict its coding potential: CPC2 (Coding Potential Calculator) [21], CNCl (Coding-Non-Coding Index) [22], CPAT (Coding Potential Assessment Tool) [23], pfam protein domain analysis [24]. Based on the mode of action of IncRNAs and their target genes, two methods are used for predicting the target genes of IncRNAs: (1) IncRNA regulates the expression of its neighboring genes, which is mainly predicted based on the position between IncRNA and the gene. The neighboring genes within $100 \mathrm{~kb}$ of the IncRNA are target genes; (2) To predict the trans-target genes of IncRNA by analyzing the correlation between IncRNA and mRNA expression among samples. The mapped reads of each sample were assembled, and the gene and IncRNA expression levels were quantified based on fragments per kilobase of transcript per million fragments mapped (FPKM) using the StringTie software [25]. The DESeq2 software package was used to detect differentially expressed IncRNAs (DELs) and differentially expressed genes (DEGs) with criteria of $\log _{2} \mid$ fold change| $>1$ and $P<0.05$ [26].

\section{miRNA data analysis}

The raw data were subjected to quality control in order to obtain clean reads as described hereafter. Sequences with a low quality value were removed from each sample. Reads with an unknown base $\mathrm{N}$ ( $\mathrm{N}$ is an unrecognizable base) content greater than or equal to $10 \%$ were removed. Reads without a $3^{\prime}$ linker sequence were removed. The $3^{\prime}$ linker sequences were cut off. Sequences shorter than 18 or longer than 30 nucleotides were removed. Clean reads were aligned with the Silva, GtRNAdb, Rfam, and Repbase databases to filter ncRNA, such as ribosomal RNA (rRNA), transfer RNA (tRNA), small nuclear RNA (snRNA), small nucleolar RNA (snoRNA), and repeating sequences, in order to obtain unannotated reads containing miRNA. Unannotated reads were mapped to the reference genome (Gallus-gallus.GRCg6a-96) using Bowtie software [27]. Known miRNAs were identified by mapping the matched mature miRNAs in miRBase (v22) to the reference genome. For unannotated reads that matched the reference genome sequences miRDeep2 was used to predict novel miRNAs [28]. The expression of miRNA in each sample was quantified and normalized by the TPM algorithm (TPM = Readcount*1,000,000/Mapped Reads) [29]. Target genes were predicted by miRanda and TargetScan based on miRNA and gene sequence information [30, 31]. The DESeq2 software package was used to detect differentially expressed miRNAs (DEMs) with the criteria of $\log _{2}$ |Fold change| $>1$ and $P<0.05$ [26].

\section{Functional annotation analysis of differentially expressed RNA}

Gene Ontology (GO) enrichment analysis of the DEGs was performed using the GOseq R packages based on the Wallenius' non-central hypergeometric distribution. The KEGG is a database resource for understanding high-level functions and utilities of a biological system, such as the cell, organism, and ecosystem, from molecular-level information, especially large-scale molecular datasets generated by genome sequencing and other highthroughput experimental technologies (http://www.genome.jp/kegg/). We used the KOBAS software to test the statistical significance of DEG enrichment in Kyoto Encyclopedia of Genes and Genomes (KEGG) pathways.

\section{Construction of the ceRNA Network}


Competitive endogenous RNAs (ceRNAs) are novel transcriptional regulators that can modulate each other's expression through competitive binding. For example, miRNA can silence gene expression by binding to target mRNA, while IncRNAs competitively bind miRNA and affect its function, in turn downregulating gene expression [32]. Based on the regulatory pairs of differentially expressed miRNA-mRNA and miRNA-IncRNA, ceRNA networks (IncRNA-miRNA-mRNA) of the interaction between IncRNA and mRNA through shared miRNAs were predicted, and the following criteria had to be met for ceRNAs: (1) the same number of miRNAs among ceRNAs should be greater than 5; (2) $P<0.01$, and FDR $<0.01$ [33].

\section{Verification of DELs, DEGs, and DEMs}

To confirm the differentially expressed RNAs identified through RNA-seq, qRT-PCR was carried out for six DELs, six DEMs, and seven DEGs. We used the PrimeScript RT reagent kit with gDNA (Tiangen Biotech Co. Ltd., Beijing, China) to convert total RNA to cDNA, with random hexamers for mRNA, IncRNAs, and mRNAs, and stem-loop RT primers for miRNAs. The qPCR was performed using the SYBR Green PCR kit (Tiangen Biotech Co. Ltd., Beijing, China) according to the manufacturer's instructions. GAPDH (glyceraldehyde-3-phosphate dehydrogenase) for IncRNAs, chicken 5S for miRNAs, and HPRT (hypoxanthine guanine phosphoribosyl transferase) for mRNAs were used as internal controls. All primers used in RT-qPCR are shown in Additional file1: Table S1. BioRad CFX96 (BioRad, CA, USA) was used to perform RT-qPCR with SYBR Green PCR Master Mix (Tiangen Biotech Co. Ltd.). Each qPCR experiment was performed in triplicate, relative RNA expression levels were calculated using the $2^{-\triangle \triangle C T}$ method, and ANOVA testing via SPSS 25.0 was applied. The results were expressed as mean \pm SE, and P $\leq 0.05$ was considered statistically significant.

\section{Results}

\section{Overview of RNA transcriptomic profiles of chicken CAM tissues}

After low-quality reads were removed, 110.3-114.1 M paired-end reads (150 bp in length) for the mRNAs and IncRNAs, and 23.8-29.2 M single-end reads (50 bp in length) for the miRNAs, were obtained from the CAM of Tibetan (TC) and Chahua chicken (CH) samples (Additional file 2: Table S2). The majority of the IncRNAs (60.7\%) were intergenic long-stranded non-coding RNA (lincRNA), followed by intronic-IncRNA (17.7\%), antisense-IncRNA (12.4\%), and 9.2\% sense-IncRNA (Fig. 1a). The length of mRNAs ranged from 51 to 30,0721 bp, IncRNAs ranged from 202 to 223,626 bp, with the majority of mRNAs and IncRNAs being 201-400 bp and > 3000 bp long, respectively (Additional file 3: Fig. S1). In total, 20,912 expressed genes, 15,523 IncRNAs (3,194 known), and 1,439 miRNAs were identified in the CAM tissues of TC and $\mathrm{CH}$. The 1,439 miRNAs included 471 known and 968 novel miRNAs, and most of the miRNA reads were between 20 and 24 nt in length (Fig. 1b, Additional file 4: Table S3). The values of FPKM of mRNA/IncRNA and TPM of miRNA distribution were similar among the six samples (Fig. 1c, d, e).

\section{Differential expression analysis of RNAs between $\mathrm{TC}$ and $\mathrm{CH}$}

We found 389 DELs, 73 DEMs, and 354 DEGs between the TC and CH groups, among which 194 DELs, 46 DEMs, and 180 DEGs were upregulated, whereas 195 DELs, 27 DEMs, and 174 DEGs were downregulated in the Tibetan chickens compared to Chahua chickens (Fig. 2, Additional file 5: Table S4). The DELs, DEMs, and DEGs were classified into two categories for the six samples in which the expressed quantity of the DELs, DEMs, and DEGs had good repeatability within groups respectively (Additional file 3: Fig. S2). 


\section{Functional analysis of differentially expressed non-coding RNAs (DELs and DEMs)}

For 389 DELs, we predicted 722 cis- and trans-target genes that were mainly involved in the GO terms of angiogenesis, blood vessel development, regulation of vasoconstriction, regulation of blood pressure, response to oxygen levels, ATP metabolic process, fatty acid metabolic process, glucuronate metabolic process, enzyme binding, and ATP binding (Fig. 3a, Additional file 6: Table S5a). The KEGG analysis revealed involvement of target genes in carbon metabolism, fatty acid metabolism, vascular smooth muscle contraction, Wnt, mTOR, MAPK, VEGF, and calcium signaling pathways (Fig. 3b, Additional file 6: Table S5b).

A total of 1,766 target genes were predicted for 73 DEMs. The target genes were mainly enriched in the GO terms of vasculogenesis, positive regulation of fatty acid oxidation, glycogen metabolic process, angiogenesis, vasculature development, response to hypoxia, oxygen metabolic process, vasodilation, ATP binding, and enzyme binding (Fig. 3c, Additional file 7: Table S6a). Notably, the enriched KEGG pathways were cysteine and methionine metabolism, amino sugar and nucleotide sugar metabolism, apoptosis, vascular smooth muscle contraction, fatty acid metabolism, carbon metabolism, vitamin B6 metabolism, MAPK, Notch, VEGF, mTOR, and calcium signaling pathways (Fig. 3d, Additional file 7: Table S6b).

\section{Comparative parsing of IncRNAs and mRNAs and functional analysis of DEGs}

To compare the exon number, open reading frame (ORF), and expression levels of IncRNA and mRNA, we need to consider the differences in structure and sequence. The number of exons corresponding to IncRNAs was mainly less than 8, whereas the number of exons of mRNA was relatively large, ranging from 1 to $>30$ (Additional file 3 : Fig. S3a, b). The majority IncRNA ORFs were mainly between 50 and 250 nt long, while the length of the ORFs of mRNAs was mainly between 100 and 1,000 nt (Additional file 3: Fig. S3c, d). Expressed mRNAs and IncRNAs were located on all chromosomes of the chicken genome (Fig. 4a). The average and maximum values of mRNA expression were higher compared to those of IncRNA expression (Fig. 4b).

The 354 DEGs were mainly enriched in GO terms of defense response, homeostatic process, regulation of lipid metabolic process, glucose homeostasis, blood microparticle, oxygen transport, blood vessel endothelial cell migration, blood circulation, and respiratory system development. Enriched KEGG pathways included fatty acid metabolism, vascular smooth muscle contraction, calcium, as well as PPAR and MAPK signaling pathways (Fig. 4c, Additional file 8: Table S7). Twelve DEGs (ACTC1, KCNMB4, NCS1, NGFR, ADAM8, CASQ2, IRF4, PTPRZ1, CALML3, ERBB4, ARR3, and NTSR1) were mainly associated with angiogenesis, blood circulation, hematopoiesis, as well as calcium and MAPK signaling pathways. Fifteen DEGs (SSTR5, NR1H4, HTR2C, APOA1, KCNB1, P3H2, CHST8, LYZ, HAO2, ACER1, ACSBG1, ELOVL2, ELOVL3, GBE, and NOX3) were related to glucose and carbohydrate metabolism, fatty acid metabolism, and lactate oxidation (Table 1). 
Table 1

Potential key differentially expressed mRNAs (DEGs), their targeted differentially expressed miRNAs (DEMs), differentially expressed IncRNAs (DELs), and their functions related to hypoxic adaption in the Tibetan chicken.

\begin{tabular}{|c|c|c|c|c|c|c|}
\hline & Gene & $\begin{array}{l}\log 2 \mathrm{FC} \\
(\mathrm{TC} / \mathrm{CH})\end{array}$ & $\begin{array}{l}P \\
\text { value }\end{array}$ & Target miRNA & Target IncRNA & $\begin{array}{l}\text { Functional } \\
\text { description }\end{array}$ \\
\hline \multirow[t]{11}{*}{ Angiogenesis } & ACTC1 & -3.4644 & 0.0122 & $\begin{array}{l}\text { gga-miR-6606- } \\
5 p\end{array}$ & $\begin{array}{l}\text { MSTRG.19949.13, } \\
\text { MSTRG.128588.3, } \\
\text { MSTRG.73129.28, } \\
\text { MSTRG.32082.2 }\end{array}$ & $\begin{array}{l}\text { Blood } \\
\text { circulation }\end{array}$ \\
\hline & KCNMB4 & 2.3558 & 0.0001 & $\begin{array}{l}\text { gga-miR-6606- } \\
5 p\end{array}$ & MSTRG.29252.7 & $\begin{array}{l}\text { Vascular } \\
\text { smooth muscle } \\
\text { contraction }\end{array}$ \\
\hline & NCS1 & -1.0050 & 0.0197 & $\begin{array}{l}\text { gga-miR-6606- } \\
\text { 5p, } \\
\text { novel_miR_815 }\end{array}$ & $\begin{array}{l}\text { MSTRG.33345.5, } \\
\text { MSTRG.140060.1, } \\
\text { MSTRG.18943.13 }\end{array}$ & $\begin{array}{l}\text { Calcium ion } \\
\text { transport }\end{array}$ \\
\hline & NGFR & 1.5519 & 0.0036 & novel_miR_676 & $\begin{array}{l}\text { MSTRG.118362.24, } \\
\text { MSTRG.12318.1, } \\
\text { MSTRG.25780.4, } \\
\text { MSTRG.128839.3, } \\
\text { MSTRG.115756.46, } \\
\text { MSTRG.41646.22, } \\
\text { MSTRG.80622.27, } \\
\text { MSTRG.44286.2, } \\
\text { MSTRG.41646.23 }\end{array}$ & $\begin{array}{l}\text { Blood vessel } \\
\text { morphogenesis, } \\
\text { blood vessel } \\
\text { development, } \\
\text { vasculature } \\
\text { development, } \\
\text { angiogenesis }\end{array}$ \\
\hline & ADAM8 & -1.3727 & 0.0470 & & & $\begin{array}{l}\text { Response to } \\
\text { hypoxia, blood } \\
\text { vessel } \\
\text { development, } \\
\text { vasculature } \\
\text { development, } \\
\text { angiogenesis }\end{array}$ \\
\hline & CASQ2 & -1.0736 & 0.0315 & $\begin{array}{l}\text { novel_miR_589, } \\
\text { novel_miR_676 }\end{array}$ & $\begin{array}{l}\text { MSTRG.73129.28, } \\
\text { MSTRG.18943.3 }\end{array}$ & $\begin{array}{l}\text { Blood } \\
\text { circulation }\end{array}$ \\
\hline & IRF4 & -1.8880 & 0.0201 & & & Hemopoiesis \\
\hline & PTPRZ1 & 1.3653 & 0.0000 & & & $\begin{array}{l}\text { Hemopoiesis, } \\
\text { hematopoietic } \\
\text { progenitor cell } \\
\text { differentiation }\end{array}$ \\
\hline & CALML3 & -1.1958 & 0.0015 & & & $\begin{array}{l}\text { Vascular } \\
\text { smooth muscle } \\
\text { contraction }\end{array}$ \\
\hline & ERBB4 & -1.2949 & 0.0102 & $\begin{array}{l}\text { novel_miR_676, } \\
\text { novel_miR_587 }\end{array}$ & $\begin{array}{l}\text { MSTRG.147643.141, } \\
\text { MSTRG.128534.3, } \\
\text { MSTRG.44329.1, } \\
\text { MSTRG.29590.15, } \\
\text { MSTRG.79818.8, } \\
\text { MSTRG.135465.5, } \\
\text { MSTRG.30620.3 }\end{array}$ & $\begin{array}{l}\text { Calcium and } \\
\text { MAPK } \\
\text { signaling } \\
\text { pathways }\end{array}$ \\
\hline & ARR3 & 1.0513 & 0.0013 & & & $\begin{array}{l}\text { MAPK } \\
\text { signaling } \\
\text { pathway }\end{array}$ \\
\hline
\end{tabular}




\begin{tabular}{|c|c|c|c|c|c|c|}
\hline & Gene & $\begin{array}{l}\log 2 F C \\
(\mathrm{TC} / \mathrm{CH})\end{array}$ & $\begin{array}{l}P \\
\text { value }\end{array}$ & Target miRNA & Target IncRNA & $\begin{array}{l}\text { Functional } \\
\text { description }\end{array}$ \\
\hline & NTSR1 & -1.5401 & 0.0140 & $\begin{array}{l}\text { novel_miR_669, } \\
\text { novel_miR_676, } \\
\text { novel_miR_567 }\end{array}$ & $\begin{array}{l}\text { MSTRG.63187.27, } \\
\text { MSTRG.71117.21, } \\
\text { MSTRG.133793.2, } \\
\text { MSTRG.29590.15, } \\
\text { MSTRG.52146.15, } \\
\text { MSTRG.72741.32, } \\
\text { MSTRG.148631.1 }\end{array}$ & $\begin{array}{l}\text { Regulation of } \\
\text { respiratory } \\
\text { gaseous } \\
\text { exchange, } \\
\text { Calcium } \\
\text { signaling } \\
\text { pathway }\end{array}$ \\
\hline \multirow[t]{12}{*}{$\begin{array}{l}\text { Energy } \\
\text { metabolism }\end{array}$} & SSTR5 & -3.8881 & 0.0054 & novel_miR_819 & MSTRG.25881.3 & $\begin{array}{l}\text { Glucose } \\
\text { homeostasis }\end{array}$ \\
\hline & $\mathrm{NR} 1 \mathrm{H} 4$ & -1.1224 & 0.0179 & novel_miR_676 & $\begin{array}{l}\text { MSTRG.99917.37, } \\
\text { MSTRG.64717.15, } \\
\text { MSTRG.99917.39, } \\
\text { MSTRG.99917.35 }\end{array}$ & $\begin{array}{l}\text { Glucose } \\
\text { homeostasis, } \\
\text { response to } \\
\text { oxygen- } \\
\text { containing } \\
\text { compound }\end{array}$ \\
\hline & HTR2C & -1.3476 & 0.0000 & & & $\begin{array}{l}\text { Regulation of } \\
\text { lipid metabolic } \\
\text { process }\end{array}$ \\
\hline & APOA1 & 1.1034 & 0.0068 & & & $\begin{array}{l}\text { Regulation of } \\
\text { lipid metabolic } \\
\text { process }\end{array}$ \\
\hline & KCNB1 & -1.1800 & 0.0000 & & & $\begin{array}{l}\text { Glucose } \\
\text { homeostasis, } \\
\text { response to } \\
\text { oxygen- } \\
\text { containing } \\
\text { compound }\end{array}$ \\
\hline & P3H2 & -1.0044 & 0.0135 & & & $\begin{array}{l}\text { Carbohydrate } \\
\text { binding }\end{array}$ \\
\hline & CHST8 & -1.9553 & 0.0013 & $\begin{array}{l}\text { novel_miR_693, } \\
\text { novel_miR_775 }\end{array}$ & & $\begin{array}{l}\text { Carbohydrate } \\
\text { metabolic } \\
\text { process }\end{array}$ \\
\hline & LYZ & -1.0365 & 0.0050 & & & $\begin{array}{l}\text { Carbohydrate } \\
\text { metabolic } \\
\text { process }\end{array}$ \\
\hline & $\mathrm{HAO} 2$ & -1.5483 & 0.0085 & novel_miR_669 & & $\begin{array}{l}\text { Carbon } \\
\text { metabolism, } \\
\text { lactate } \\
\text { oxidation }\end{array}$ \\
\hline & ACER1 & 1.5111 & 0.0032 & & & $\begin{array}{l}\text { Regulation of } \\
\text { lipid metabolic } \\
\text { process }\end{array}$ \\
\hline & ACSBG1 & 1.1154 & 0.0000 & & & $\begin{array}{l}\text { Fatty acid } \\
\text { metabolism }\end{array}$ \\
\hline & ELOVL2 & -5.1386 & 0.0480 & & & $\begin{array}{l}\text { Fatty acid } \\
\text { metabolism }\end{array}$ \\
\hline
\end{tabular}




\begin{tabular}{|cccccc|}
\hline Gene & $\begin{array}{l}\text { Log2FC } \\
\text { (TC/CH) }\end{array}$ & $\begin{array}{l}\text { P } \\
\text { value }\end{array}$ & Target miRNA & Target IncRNA & $\begin{array}{l}\text { Functional } \\
\text { description }\end{array}$ \\
\hline ELOVL3 & 2.0872 & 0.0146 & novel_miR_867 & & $\begin{array}{l}\text { Fatty acid } \\
\text { metabolism }\end{array}$ \\
\hline GBE & -1.0082 & 0.0072 & novel_miR_85 & MSTRG.128588.4 & $\begin{array}{l}\text { Oxygen } \\
\text { transport, } \\
\text { oxygen binding, } \\
\text { reactive oxygen } \\
\text { species } \\
\text { metabolic } \\
\text { process }\end{array}$ \\
\hline NOX3 & 3.0828 & 0.0000 & & $\begin{array}{l}\text { Reactive } \\
\text { oxygen species } \\
\text { metabolic } \\
\text { process }\end{array}$ \\
\hline
\end{tabular}

\section{Construction of the ceRNA network}

We constructed a ceRNA network that yielded 529 pairs of candidate ceRNAs (IncRNA-miRNA-mRNA) from 162 DELs and 108 DEGs through 25 miRNA target-mediated relationships (Additional file 3: Fig. S4). Considering that the network contains enormous information, and each relationship cannot be displayed in the figure, we constructed a mini-ceRNA network of important RNAs. We identified 10 known mRNAs that were related to hypoxic adaptation and involved in angiogenesis and blood circulation (NGFR, ACTC1, CASQ2, ERBB4, KCNMB4, NCS1, and NTSR1) (Fig. 5a), as well as energy metabolism (SSTR5, NR1H4, and GBE) (Fig. 5b). A total of 39 IncRNAmiRNA-mRNA interactions were identified in the mini-ceRNA network constructed with these 10 DEGs and their targeted 37 DELs and 9 DEMs (Table 1, Additional file 9: Table S8).

\section{Validation of DELs, DEMs, and DEGs}

Six DELs (MSTRG.118362.24, MSTRG.25780.4, MSTRG.19949.13, MSTRG.29590.15, MSTRG.32082.2 and MSTRG.73129.28), six DEMs (gga-miR-726-3p, gga-miR-6608-3p, gga-miR-6606-5p, novel-miR-676, gga-miR-460b3p, and gga-miR-7442-5p), and seven DEGs (ARR3, NGFR, NTSR1, ADAM8, ACTC1, CASQ2, and CALML3) were measured using quantitative real-time PCR (qRT-PCR) to validate expression differences identified through RNAsEq. The results indicated that the expression levels of all RNAs were significantly different between $\mathrm{TC}$ and $\mathrm{CH}(P$ $<0.05$ ), and fold changes in expression followed the same trend in qRT-PCR and RNA-seq (Fig. 6).

\section{Discussion}

Through evolution, Tibetan chickens have developed genetic adaptability to survive in low-oxygen environments. Previous reports have shown that Tibetan chickens exhibit unique phenotypic and physiological characteristics, including enhanced blood oxygen binding capacity and increased blood circulation [11, 16]. Because it was first reported a few years ago, the ceRNA hypothesis has been widely accepted, leading to an improved understanding of human disease, as well as important advances in animal research [32,34]. The recently discovered ncRNAs represent a new type of master regulator that affects gene expression and modulates a variety of cellular processes. Based on these theories, we constructed a ceRNA regulatory network in order to clarify the molecular mechanism of Tibetan chicken embryo CAM adaptation to hypoxic environments. 
The CAM, an important respiratory and circulatory organ for chicken embryo development, contains a large number of blood vessels, and hypoxia can induce increased blood vessel density [17, 35]. From the constructed ceRNA network, we identified several miRNAs, including down-regulated novel-miR-589, novel-miR-815, novel-miR85, novel-miR-669, as well as up-regulated miR-6606-5p, novel-miR-676, novel-miR-589, novel-miR-815, novel-miR85, and novel-miR-567. Among these, miR-6606-5p was significantly up-regulated in the Tibetan chicken, and its target differentially expressed mRNAs (ACTC1, KCNMB4, and NCS1) were shown to be involved in vascular development under hypoxic conditions. ACTC1 was enriched in the GO term of blood circulation, while KCNMB4 has been shown to regulate blood pressure and was enriched in the $\mathrm{GO}$ terms of regulation of vasoconstriction, ion transport, and vascular smooth muscle contraction pathway [36]. Previous studies also found that NCS1 regulates calcium ion transport and that $\mathrm{Ca}^{2+}$ is necessary for the activity of HIF-1, which is a major transcriptional regulator of cells and development in response to hypoxia $[37,38]$. It is worth mentioning that with the exception of miR6606-5p, other differentially expressed miRNAs, including miRNA-155, miRNA-302a, miR-302b-3p, miR-302b-5p, miR-302c-3p, miR-460b-3p, and miR-460b-5p, also play important roles in angiogenesis under hypoxia. The miRNA-155 promotes HIF-1a activity during prolonged hypoxia and participates in the PI3K/AKT pathway [39, 40]. Previous studies have shown that the miR-302 family (miR-302a/b/c/d) suppresses the proliferation, migration, and angiogenesis of vascular endothelial cells by targeting VEGFA [41-43]. The miR-460b-3p and miR-460b-5p were identified in animal models of hypoxic pulmonary hypertension and were involved in the regulation of HIF-1a $[44,45]$. Moreover, other differentially expressed mRNAs (NGFR, ADAM8, CASQ2, IRF4, PTPRZ1, CALML3, ERBB4, ARR3, and NTSR1) were enriched in blood vessel development, angiogenesis, blood circulation, hematopoiesis, response to hypoxia, oxygen transport, vascular smooth muscle contraction, calcium and MAPK signaling pathways. For example, NGFR is the receptor of NGF, which can induce chick CAM neovascularization [46]. Studies have shown that ADAM8 is significantly induced by hypoxia and plays a role in the proliferation and migration of endothelial cells during angiogenesis $[47,48]$. Therefore, we speculate that the enhanced tolerance of Tibetan chicken embryo CAM under hypoxic conditions is ascribed to miRNA-mediated modulation of the related target mRNAs, further regulating HIF, which enables it to maintain hypoxic adaptation via the promotion of angiogenesis and blood circulation.

Glucose uptake and carbohydrate metabolism are the basis for the maintenance of normal physiological functions in humans and animals. Under hypoxic conditions, oxygen and carbon dioxide metabolism mainly depend on mitochondrial respiration and make use of adenosine triphosphate (ATP). At present, a number of studies have shown the key regulatory role of energy metabolism, including glucose, carbohydrate, and lipid metabolic processes, among others, during hypoxic adaptation [49-52]. In the current research, from the constructed ceRNA network, we identified seven differentially expressed miRNAs (novel-miR-819, novel-miR-676, novel-miR-85, novel-miR-693, novel-miR-775, novel-miR-669, and novel-miR-867) and sixteen differentially expressed mRNAs related to energy metabolism including glycosylation, glucose metabolism process, carbohydrate metabolism process, fatty acid metabolism, and ATP binding. For example, SSTR5 and NR1H4 are essential for glucose homeostasis and play a pivotal role in glucose metabolism in animals [53, 54]. Cortisol regulates the metabolism of mouse adipose cells through the serotonin receptor gene HTR2C, and genetic variation of the APOA1 gene is linked to lipid metabolism and cardiovascular disease risk [55, 56]. It should be considered that more differentially expressed mRNAs (KCNB1, P3H2, CHST8, LYZ, HAO2, ACER1, ACSBG1, ELOVL2, ELOVL3, GBE, and NOX3) were targeted by key miRNAs, and several studies have shown that these mRNAs are also involved in energy metabolism. Therefore, we speculate that Tibetan chickens have enhanced energy metabolism due to the function of these RNAs, allowing for adaptation to hypoxic conditions. 
Accumulating evidence indicates that IncRNAs play the role of ceRNAs (or miRNA sponges) in a variety of biological processes, including high-altitude adaptation. Such as LINC-PINT and LINC00599 polymorphisms are associated with high-altitude pulmonary edema in Chinese populations [57]. Another study reported the expression profiles of IncRNAs in mice with high-altitude hypoxia-induced brain injury and provided new insights into the molecular mechanism of its treatment [58]. In addition, a previous study reported the expression profiles of IncRNAs responsible for fatness and fatty acid composition traits in Tibetan pigs [59]. In the current work, we found that the aforementioned differentially expressed mRNAs involved in angiogenesis and energy metabolism were targeted by 37 differentially expressed IncRNAs in the ceRNA network, suggesting that these IncRNAs may also function as miRNA sponges and may play a role in the hypoxic adaptation of Tibetan chicken embryos with regard to angiogenesis and energy metabolism.

Based on the ceRNA theory and the ceRNA network constructed in this study, we proposed the mode of action of differentially expressed IncRNAs, miRNAs, and mRNAs during hypoxic adaptation of Tibetan chicken embryos (Fig. 7). Under hypoxic conditions, miRNAs act as key regulators to modulate the up-regulation or down-regulation of important differentially expressed mRNAs. As a consequence, the angiogenesis/blood circulation of chorioallantoic capillaries and energy metabolism, such as glucose/carbohydrate metabolism, were stimulated, leading to the enhanced hypoxia adaptability of Tibetan chicken embryos. In this process, some IncRNAs act as ceRNAs to competitively bind the MRE of miRNAs, which may indirectly affect the expression of mRNA.

\section{Conclusions}

In conclusion, 389 DELs, 73 DEMs, and 354 DEGs were identified between Tibetan and Chahua chickens, the transcriptomic data revealed several key candidate ceRNAs that may play high-priority roles in the hypoxic adaptation of Tibetan chickens by regulating angiogenesis and energy metabolism. These results provide insight into the molecular mechanisms of hypoxic adaptation regulatory networks from the perspective of coding and non-coding RNAs.

\section{Abbreviations}

IncRNAs: long non-coding RNA; miRNA: microRNA; TC: Tibetan chicken; $\mathrm{CH}$ : Chahua chicken; CAM: Chorioallantoic membrane; DEG: Differentially expressed gene; DEL: Differentially expressed IncRNA; DEM: Differentially expressed miRNA; CeRNA: Competing endogenous RNA; GO: Gene Ontology; KEGG: Kyoto Encyclopedia of Genes and Genomes; ORF: Open reading frame

\section{Declarations}

\section{Ethics approval and consent to participate}

All animal work was conducted following the guidelines for the care and use of experimental animals. The experiments and animal care protocol were approved by the animal welfare committee of the State Key Laboratory for Agro-Biotechnology of the China Agricultural University (approval number, XK257).

\section{Consent for publication}




\section{Availability of data and materials}

All RNA-seq data were deposited in the Gene Expression Omnibus under accession number GSE160324. Other supporting materials are included as additional files.

\section{Competing interests}

The authors declare that they have no competing interests.

\section{Funding}

This work was supported by the National Natural Science Foundation of China (31972532), the China Agricultural Research System (ACRS-40-K05), and the Innovation Base Cultivation and Development Project (Z171100002217072).

\section{Authors' contributions}

Y.Z., and H.Z. designed the research; Y.Z., W.S., and B.Z. collected samples, extracted RNAs and performed qPCR verification experiments; Y.Z. performed most of the bioinformatics studies; Y.Z., H.Z., and W.K. wrote and revised the manuscript; All authors reviewed the manuscript.

\section{Acknowledgements}

The authors would also like to thank BioMarker Technology (Beijing, China) for the sequencing services.

\section{References}

1. Kochan-Jamrozy K, Kroliczewski J, Moszynska A, Collawn JF, Bartoszewski R. miRNA networks modulate human endothelial cell adaptation to cyclic hypoxia. Cell Signal 2019; 54:150-160.

2. Gupta A, Ragumani S, Sharma YK, Ahmad Y, Khurana P. Analysis of Hypoxiamir-Gene Regulatory Network Identifies Critical MiRNAs Influencing Cell-Cycle Regulation Under Hypoxic Conditions. MicroRNA 2019; 8(3):223-236.

3. Zhao LL, Wu H, Sun JL, Liao L, Cui C, Liu Q, et al. MicroRNA-124 regulates lactate transportation in the muscle of largemouth bass (micropterus salmoides) under hypoxia by targeting MCT1. Aquatic toxicology 2020; 218:105359.

4. Taguchi A, Yanagisawa K, Tanaka M, Cao K, Matsuyama Y, Goto H, et al. Identification of hypoxia-inducible factor-1 alpha as a novel target for miR-17-92 microRNA cluster. Cancer research 2008; 68(14):5540-5545.

5. Lei Z, Li B, Yang Z, Fang H, Zhang GM, Feng ZH, et al. Regulation of HIF-1alpha and VEGF by miR-20b tunes tumor cells to adapt to the alteration of oxygen concentration. PLoS ONE 2009; 4(10):e7629. 
6. Rane S, He M, Sayed D, Vashistha H, Malhotra A, Sadoshima J, et al. Downregulation of miR-199a derepresses hypoxia-inducible factor-1alpha and Sirtuin 1 and recapitulates hypoxia preconditioning in cardiac myocytes. Circulation research 2009; 104(7):879-886.

7. Huang L, Wang W, Hu Z, Guan C, Li W, Jiang X. Hypoxia and IncRNAs in gastrointestinal cancers. Pathology, research and practice 2019; 215(12):152687.

8. Shih JW, Chiang WF, Wu ATH, Wu MH, Wang LY, Yu YL, et al. Long noncoding RNA LncHIFCAR/MIR31HG is a HIF-1alpha co-activator driving oral cancer progression. Nature communications 2017; 8:15874.

9. Wang X, Wang Y, Li L, Xue X, Xie H, Shi H, et al. A IncRNA coordinates with Ezh2 to inhibit HIF-1alpha transcription and suppress cancer cell adaption to hypoxia. Oncogene 2020; 39(9):1860-1874.

10. Bao HG, Zhao CJ, Li JY, Zhang H, Wu C. A comparison of mitochondrial respiratory function of Tibet chicken and Silky chicken embryonic brain. Poult Sci 2007; 86(10):2210-2215.

11. Gou X, Li N, Lian L, Yan D, Zhang H, Wei Z, et al. Hypoxic adaptations of hemoglobin in Tibetan chick embryo: high oxygen-affinity mutation and selective expression. Comp Biochem Physiol B Biochem Mol Biol 2007; 147(2):147-155.

12. Zhang H, Wu CX, Chamba Y, Ling Y. Blood characteristics for high altitude adaptation in Tibetan chickens. Poult Sci 2007; 86(7):1384-1389.

13. Zhang H, Wang XT, Chamba Y, Ling Y, Wu CX. Influences of hypoxia on hatching performance in chickens with different genetic adaptation to high altitude. Poult Sci 2008; 87(10):2112-2116.

14. Li M, Zhao C. Study on Tibetan Chicken embryonic adaptability to chronic hypoxia by revealing differential gene expression in heart tissue. Science in China Series C, Life sciences 2009; 52(3):284-295.

15. Zhang Q, Gou W, Wang X, Zhang Y, Ma J, Zhang H, et al. Genome Resequencing Identifies Unique Adaptations of Tibetan Chickens to Hypoxia and High-Dose Ultraviolet Radiation in High-Altitude Environments. Genome biology and evolution 2016; 8(3):765-776.

16. Zhang Y, Gou W, Ma J, Zhang H, Zhang Y, Zhang H. Genome methylation and regulatory functions for hypoxic adaptation in Tibetan chicken embryos. PeerJ 2017; 5:e3891.

17. Zhang Y, Zheng X, Zhang Y, Zhang H, Zhang X, Zhang H. Comparative transcriptomic and proteomic analyses provide insights into functional genes for hypoxic adaptation in embryos of Tibetan chickens. Scientific reports 2020; 10(1):11213.

18. Li J, Ma W, Zeng P, Wang J, Geng B, Yang J, et al. LncTar: a tool for predicting the RNA targets of long noncoding RNAs. Briefings in bioinformatics 2015; 16(5):806-812.

19. Lv J, Cui W, Liu H, He H, Xiu Y, Guo J, et al. Identification and characterization of long non-coding RNAs related to mouse embryonic brain development from available transcriptomic data. PLoS ONE 2013; 8(8):e71152.

20. Kelley D, Rinn J. Transposable elements reveal a stem cell-specific class of long noncoding RNAs. Genome Biol 2012; 13(11):R107.

21. Kong L, Zhang Y, Ye ZQ, Liu XQ, Zhao SQ, Wei L, et al. CPC: assess the protein-coding potential of transcripts using sequence features and support vector machine. Nucleic Acids Res 2007; 35(Web Server issue):W345349.

22. Sun L, Luo H, Bu D, Zhao G, Yu K, Zhang C, et al. Utilizing sequence intrinsic composition to classify proteincoding and long non-coding transcripts. Nucleic Acids Res 2013; 41(17):e166.

23. Wang L, Park HJ, Dasari S, Wang S, Kocher JP, Li W. CPAT: Coding-Potential Assessment Tool using an alignment-free logistic regression model. Nucleic Acids Res 2013; 41(6):e74. 
24. Finn RD, Bateman A, Clements J, Coggill P, Eberhardt RY, Eddy SR, et al. Pfam: the protein families database. Nucleic Acids Res 2014; 42(Database issue):D222-230.

25. Pertea M, Kim D, Pertea GM, Leek JT, Salzberg SL. Transcript-level expression analysis of RNA-seq experiments with HISAT, StringTie and Ballgown. Nature protocols 2016; 11(9):1650-1667.

26. Love MI, Huber W, Anders S. Moderated estimation of fold change and dispersion for RNA-seq data with DESeq2. Genome Biol 2014; 15(12):550.

27. Langmead B, Trapnell C, Pop M, Salzberg SL. Ultrafast and memory-efficient alignment of short DNA sequences to the human genome. Genome Biol 2009; 10(3):R25.

28. Friedlander MR, Mackowiak SD, Li N, Chen W, Rajewsky N. miRDeep2 accurately identifies known and hundreds of novel microRNA genes in seven animal clades. Nucleic Acids Res 2012; 40(1):37-52.

29. Li B, Ruotti V, Stewart RM, Thomson JA, Dewey CN. RNA-Seq gene expression estimation with read mapping uncertainty. Bioinformatics 2010; 26(4):493-500.

30. Betel D, Wilson M, Gabow A, Marks DS, Sander C. The microRNA.org resource: targets and expression. Nucleic Acids Res 2008; 36(Database issue):D149-153.

31. Lewis BP, Shih IH, Jones-Rhoades MW, Bartel DP, Burge CB. Prediction of mammalian microRNA targets. Cell 2003; 115(7):787-798.

32. Salmena L, Poliseno L, Tay Y, Kats L, Pandolfi PP. A ceRNA hypothesis: the Rosetta Stone of a hidden RNA language? Cell 2011; 146(3):353-358.

33. Li JH, Liu S, Zhou H, Qu LH, Yang JH. starBase v2.0: decoding miRNA-ceRNA, miRNA-ncRNA and protein-RNA interaction networks from large-scale CLIP-Seq data. Nucleic Acids Res 2014; 42(Database issue):D92-97.

34. Su X, Xing J, Wang Z, Chen L, Cui M, Jiang B. microRNAs and ceRNAs: RNA networks in pathogenesis of cancer. Chinese journal of cancer research = Chung-kuo yen cheng yen chiu 2013; 25(2):235-239.

35. Dusseau JW, Hutchins PM. Hypoxia-induced angiogenesis in chick chorioallantoic membranes: a role for adenosine. Respir Physiol 1988; 71(1):33-44.

36. Feng Y, Liu Y, Cao PX, Sun X, Li KX, Li XY, et al. Estrogen-dependent MicroRNA-504 Expression and Related Baroreflex Afferent Neuroexcitation via Negative Regulation on KCNMB4 and KCa1.1 beta4-subunit Expression. Neuroscience 2020; 442:168-182.

37. Schaad NC, De Castro E, Nef S, Hegi S, Hinrichsen R, Martone ME, et al. Direct modulation of calmodulin targets by the neuronal calcium sensor NCS-1. Proc Natl Acad Sci U S A 1996; 93(17):9253-9258.

38. Hui AS, Bauer AL, Striet JB, Schnell PO, Czyzyk-Krzeska MF. Calcium signaling stimulates translation of HIFalpha during hypoxia. FASEB journal : official publication of the Federation of American Societies for Experimental Biology 2006; 20(3):466-475.

39. Bruning U, Cerone L, Neufeld Z, Fitzpatrick SF, Cheong A, Scholz CC, et al. MicroRNA-155 promotes resolution of hypoxia-inducible factor 1alpha activity during prolonged hypoxia. Mol Cell Biol 2011; 31(19):4087-4096.

40. Wu X, Li J, Yang X, Bai X, Shi J, Gao J, et al. miR-155 inhibits the formation of hypertrophic scar fibroblasts by targeting HIF-1alpha via PI3K/AKT pathway. Journal of molecular histology 2018; 49(4):377-387.

41. Qin C, Zha W, Fan R, Ding H, Xu Y, Wang C. MicroRNA302a inhibits cell proliferation and invasion, and induces cell apoptosis in hepatocellular carcinoma by directly targeting VEGFA. Molecular medicine reports 2017; 16(5):6360-6367. 
42. Sun $Y$, Xiong $X$, Wang $X$. RELA promotes hypoxia-induced angiogenesis in human umbilical vascular endothelial cells via LINC01693/miR-302d/CXCL12 axis. J Cell Biochem 2019; 120(8):12549-12558.

43. Cao YP, Pan M, Song YL, Zhang HL, Sui HT, Shan BC, et al. MiR-302 a/b/c suppresses tumor angiogenesis in hepatocellular carcinoma by targeting MACC1. European review for medical and pharmacological sciences 2019; 23(18):7863-7873.

44. Fraidenburg DR, Machado RF. A Review of Transcriptome Analysis in Pulmonary Vascular Diseases. Methods Mol Biol 2018; 1783:259-277.

45. Liu P, Yang F, Zhuang Y, Xiao Q, Cao H, Zhang C, et al. Dysregulated expression of microRNAs and mRNAs in pulmonary artery remodeling in ascites syndrome in broiler chickens. Oncotarget 2017; 8(2):1993-2007.

46. Ribatti D, Nico B, Belloni AS, Vacca A, Roncali L, Nussdorfer GG. Angiogenic activity of leptin in the chick embryo chorioallantoic membrane is in part mediated by endogenous fibroblast growth factor-2. International journal of molecular medicine 2001; 8(3):265-268.

47. Gao Y, Yu X, Zhang F, Dai J. Propofol inhibits pancreatic cancer progress under hypoxia via ADAM8. Journal of hepato-biliary-pancreatic sciences 2019; 26(6):219-226.

48. Mahoney ET, Benton RL, Maddie MA, Whittemore SR, Hagg T. ADAM8 is selectively up-regulated in endothelial cells and is associated with angiogenesis after spinal cord injury in adult mice. J Comp Neurol 2009; 512(2):243-255.

49. Meir JU, York JM, Chua BA, Jardine W, Hawkes LA, Milsom WK. Reduced metabolism supports hypoxic flight in the high-flying bar-headed goose (Anser indicus). eLife 2019; 8.

50. Yang J, Li WR, Lv FH, He SG, Tian SL, Peng WF, et al. Whole-Genome Sequencing of Native Sheep Provides Insights into Rapid Adaptations to Extreme Environments. Mol Biol Evol 2016; 33(10):2576-2592.

51. Schippers MP, Ramirez O, Arana M, Pinedo-Bernal P, McClelland GB. Increase in carbohydrate utilization in high-altitude Andean mice. Curr Biol 2012; 22(24):2350-2354.

52. Gangwar A, Paul S, Ahmad Y, Bhargava K. Intermittent hypoxia modulates redox homeostasis, lipid metabolism associated inflammatory processes and redox post-translational modifications: Benefits at high altitude. Scientific reports 2020; 10(1):7899.

53. Wang XP, Yang J, Norman MA, Magnusson J, DeMayo FJ, Brunicardi FC. SSTR5 ablation in islet results in alterations in glucose homeostasis in mice. FEBS letters 2005; 579(14):3107-3114.

54. Ma K, Saha PK, Chan L, Moore DD. Farnesoid X receptor is essential for normal glucose homeostasis. The Journal of clinical investigation 2006; 116(4):1102-1109.

55. Priyadarshini S, Pradhan B, Griebel P, Aich P. Cortisol regulates immune and metabolic processes in murine adipocytes and macrophages through HTR2c and HTR5a serotonin receptors. Eur J Cell Biol 2018; 97(7):483492.

56. Lai CQ, Parnell LD, Ordovas JM. The APOA1/C3/A4/A5 gene cluster, lipid metabolism and cardiovascular disease risk. Current opinion in lipidology 2005; 16(2):153-166.

57. He X, Zheng J, He Y, Wang Y, Wang L, Bai M, et al. Long Non-coding RNA LINC-PINT and LINC00599 Polymorphisms are Associated With High-altitude Pulmonary Edema in Chinese. Archivos de bronconeumologia 2020; 56(6):360-364.

58. Zhang Y, Liu L, Liang C, Zhou L, Tan L, Zong Y, et al. Expression Profiles of Long Noncoding RNAs in Mice with High-Altitude Hypoxia-Induced Brain Injury Treated with Gymnadenia conopsea (L.) R. Br. Neuropsychiatric disease and treatment 2020; 16:1239-1248.

Page 15/29 
59. Shang P, Li W, Liu G, Zhang J, Li M, Wu L, et al. Identification of IncRNAs and Genes Responsible for Fatness and Fatty Acid Composition Traits between the Tibetan and Yorkshire Pigs. International journal of genomics $2019 ; 2019: 5070975$.

\section{Figures}

(a)

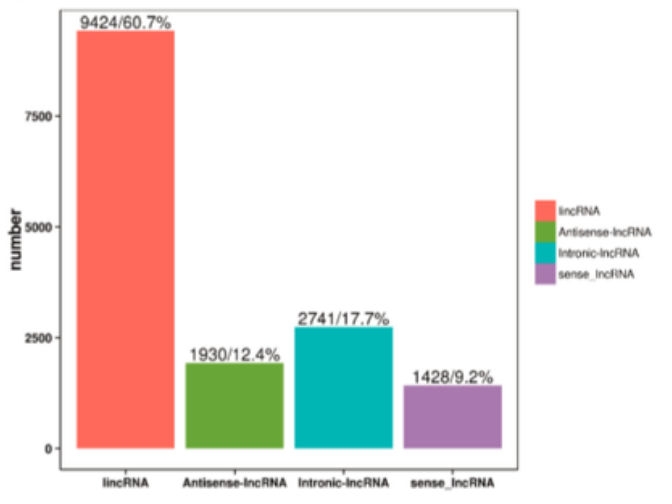

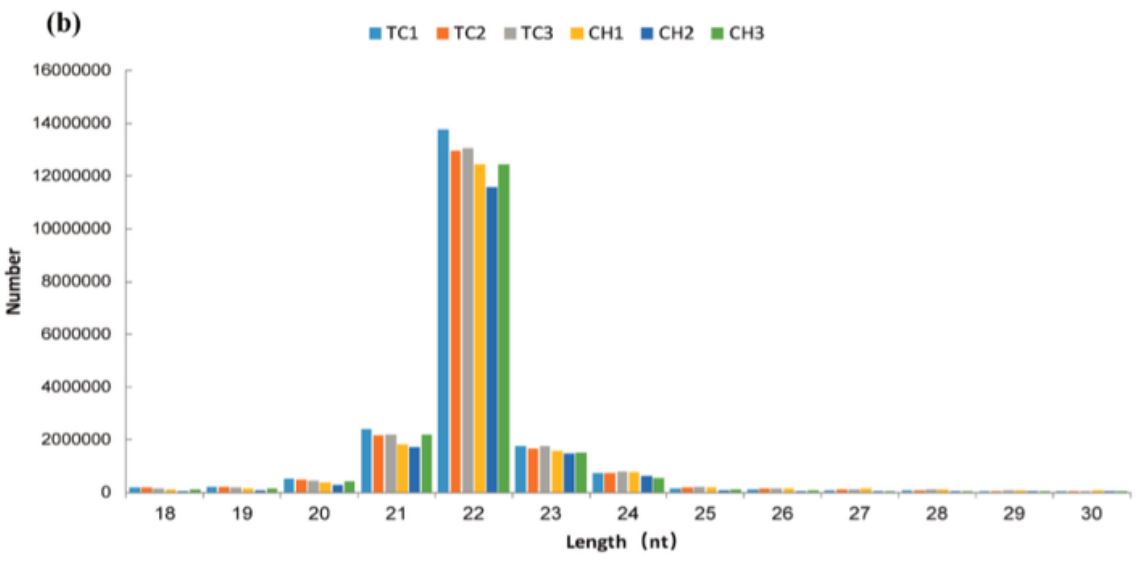

(d)

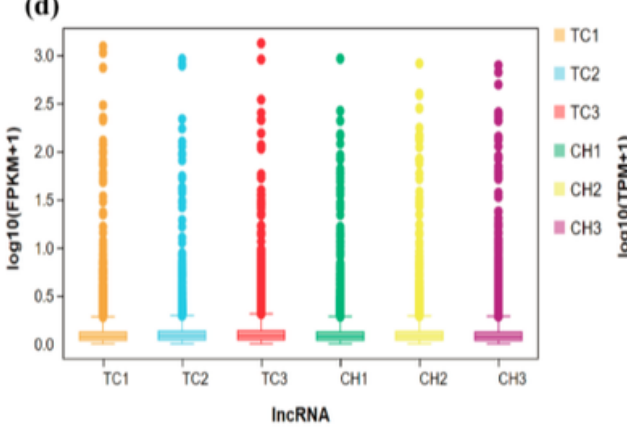

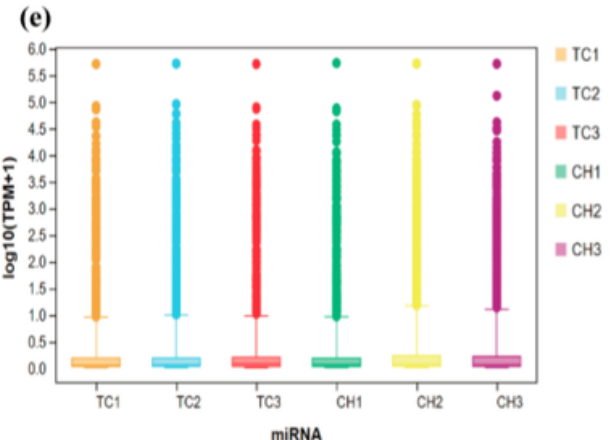

Figure 1

Comparison of the features of RNAs in the CAM of chicken embryos. (a) Statistics of long non-coding RNA, including intergenic non-coding RNAs (lincRNAs), anti-sense IncRNAs, intronic IncRNAs, and sense IncRNAs; (b) Length distribution of 1439 miRNAs; (c) Distributions of mRNA expression values (FPKM) of six samples; (d) Distributions of IncRNA expression values (FPKM) of six samples; (e) Distributions of miRNA expression values (TPM) of six samples. TC, Tibetan chicken; $\mathrm{CH}$, Chahua chicken. 
(a)

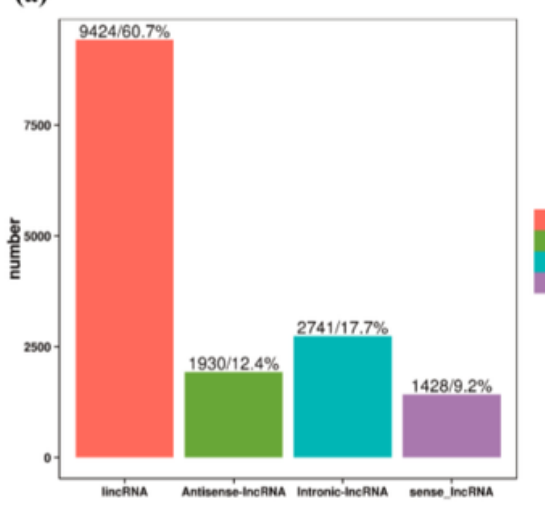

(b)

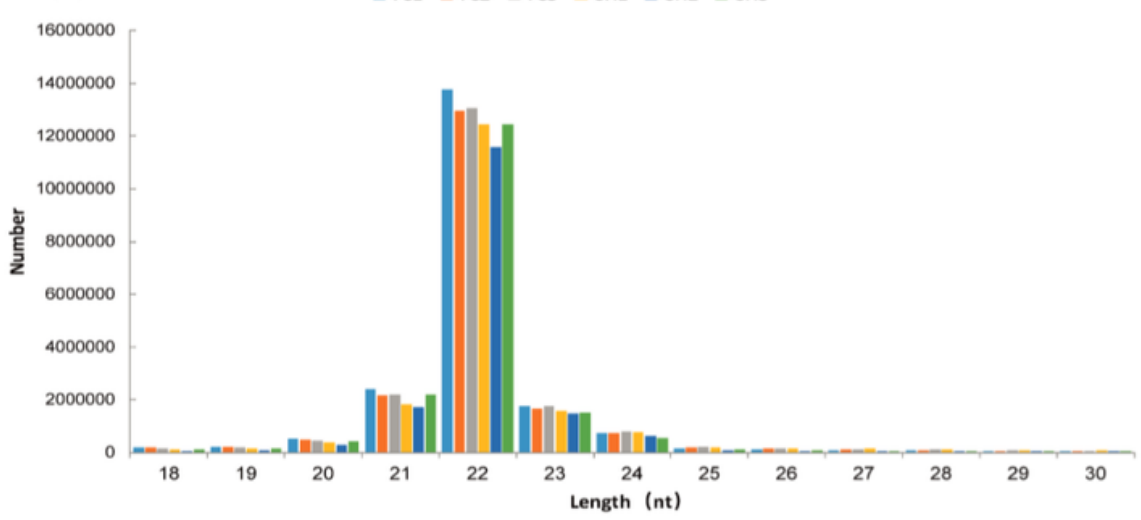

(c)

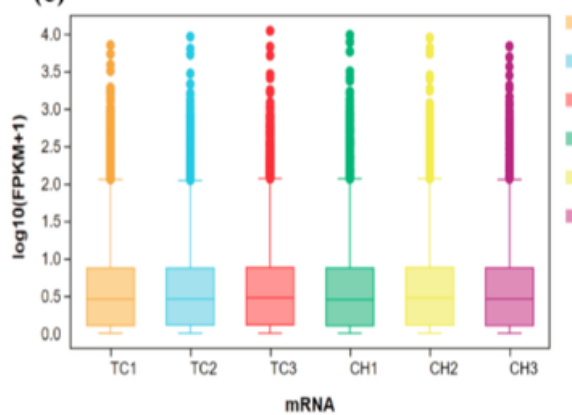

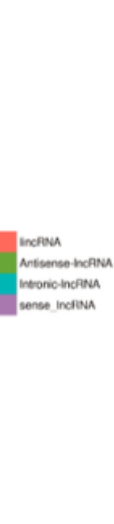

(d)

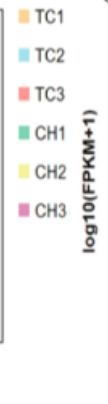

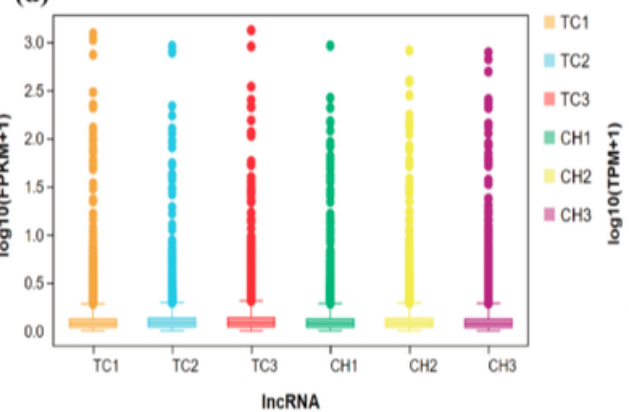

(e)

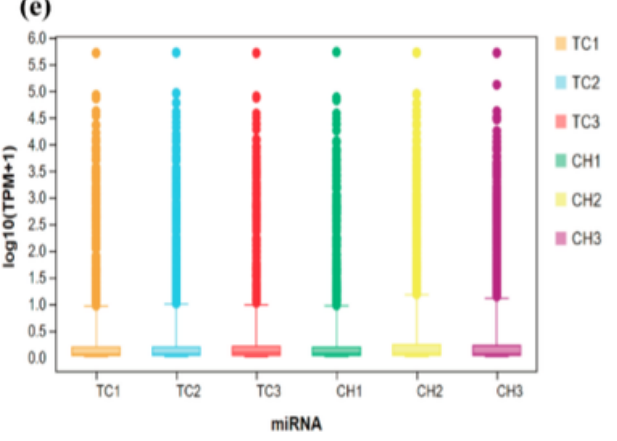

Figure 1

Comparison of the features of RNAs in the CAM of chicken embryos. (a) Statistics of long non-coding RNA, including intergenic non-coding RNAs (lincRNAs), anti-sense IncRNAs, intronic IncRNAs, and sense IncRNAs; (b) Length distribution of 1439 miRNAs; (c) Distributions of mRNA expression values (FPKM) of six samples; (d) Distributions of IncRNA expression values (FPKM) of six samples; (e) Distributions of miRNA expression values (TPM) of six samples. TC, Tibetan chicken; $\mathrm{CH}$, Chahua chicken. 
(a)

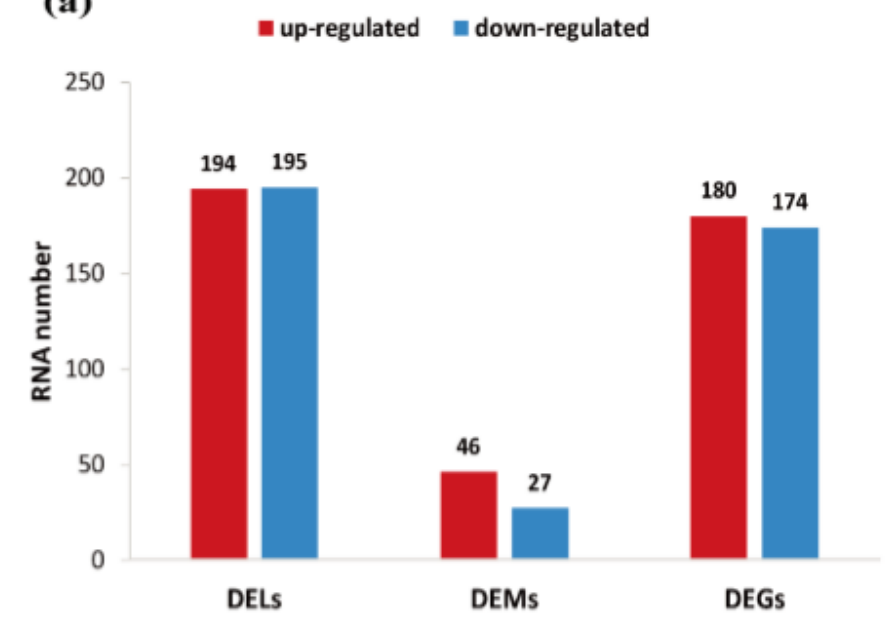

(c)

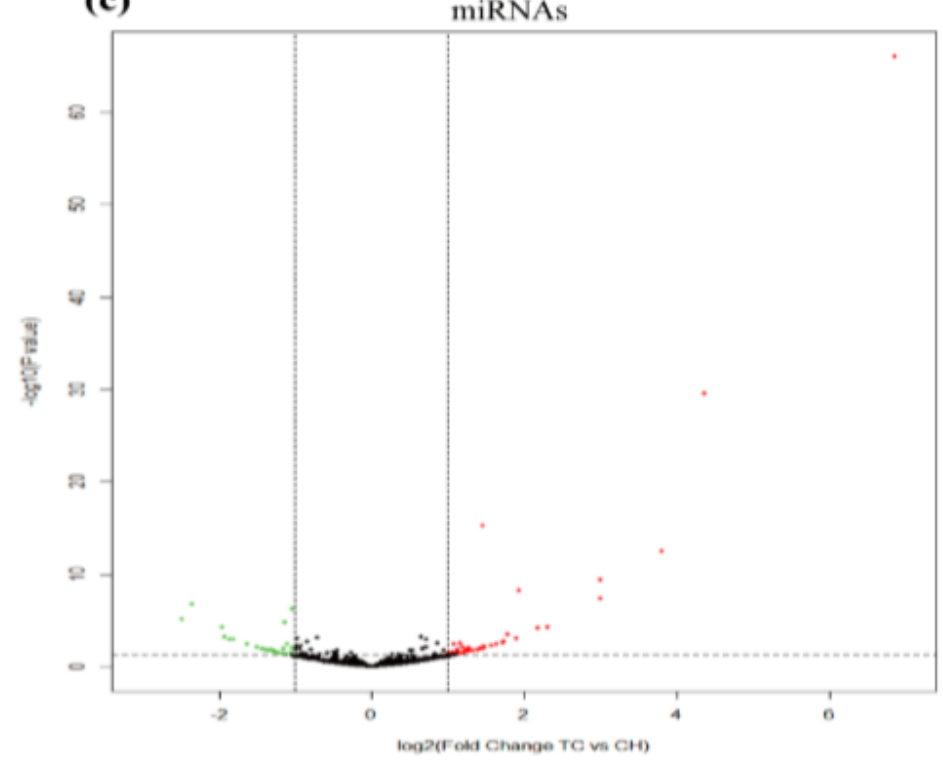

(b)
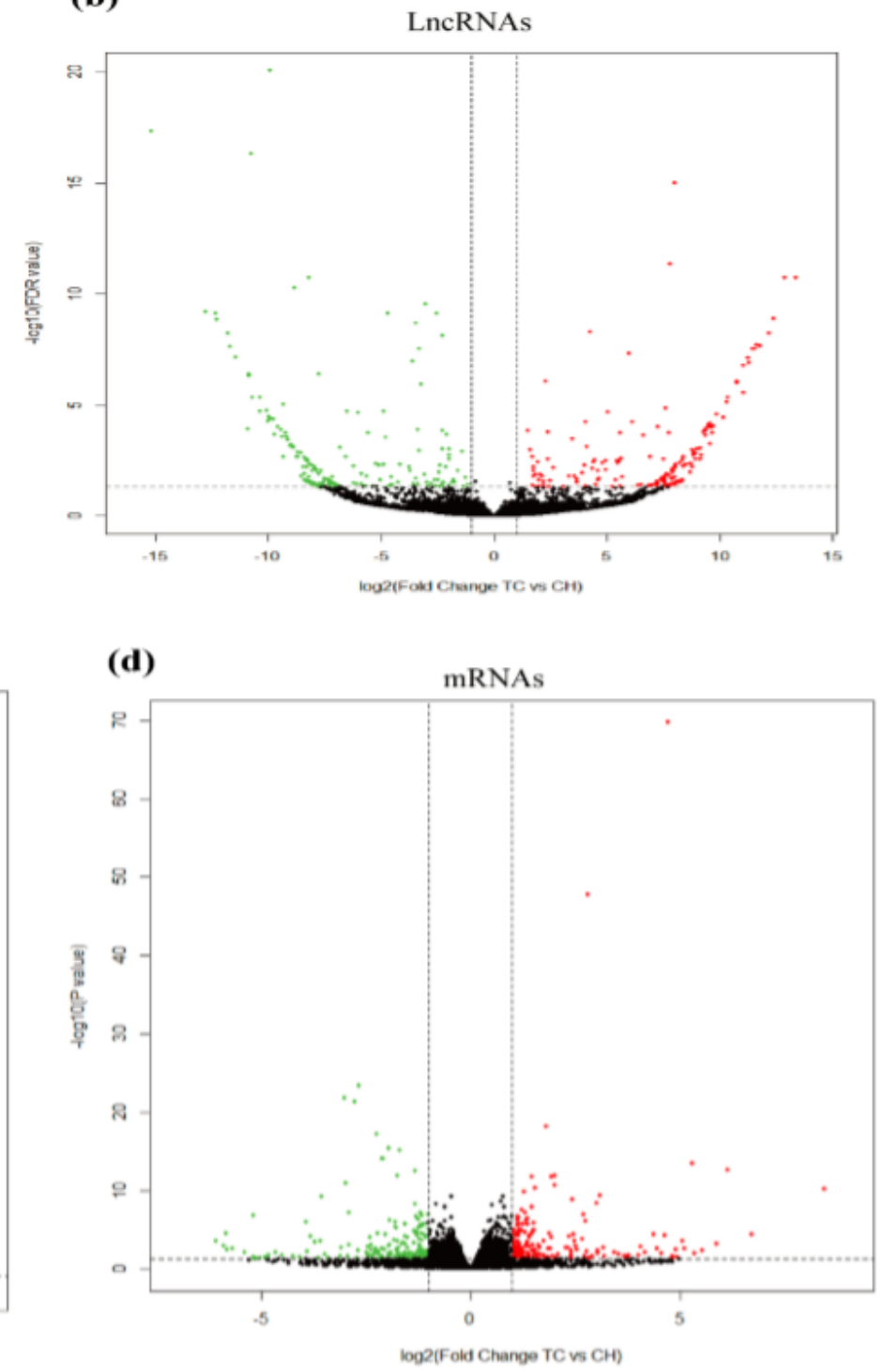

Figure 2

Identification of DELs, DEMs, and DEGs between TC and CH. Number of differentially expressed IncRNAs, miRNAs, and genes (a); Volcano plot displaying DELs (b), DEMs (c), and DEGs (d) between TC and CH. Upregulated and downregulated genes are shown in red and blue, respectively. Black dots represent genes with similar expression levels. 
(a)

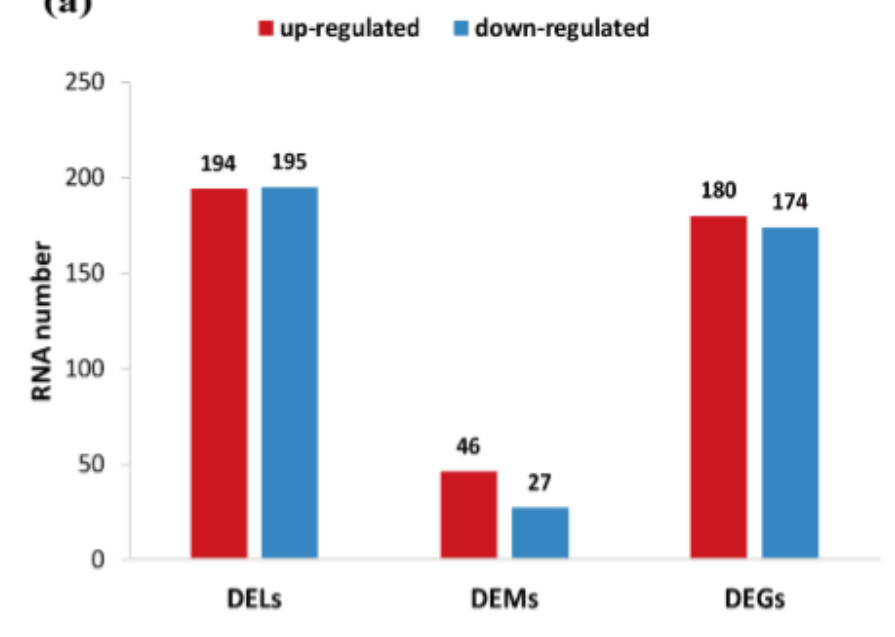

(c)

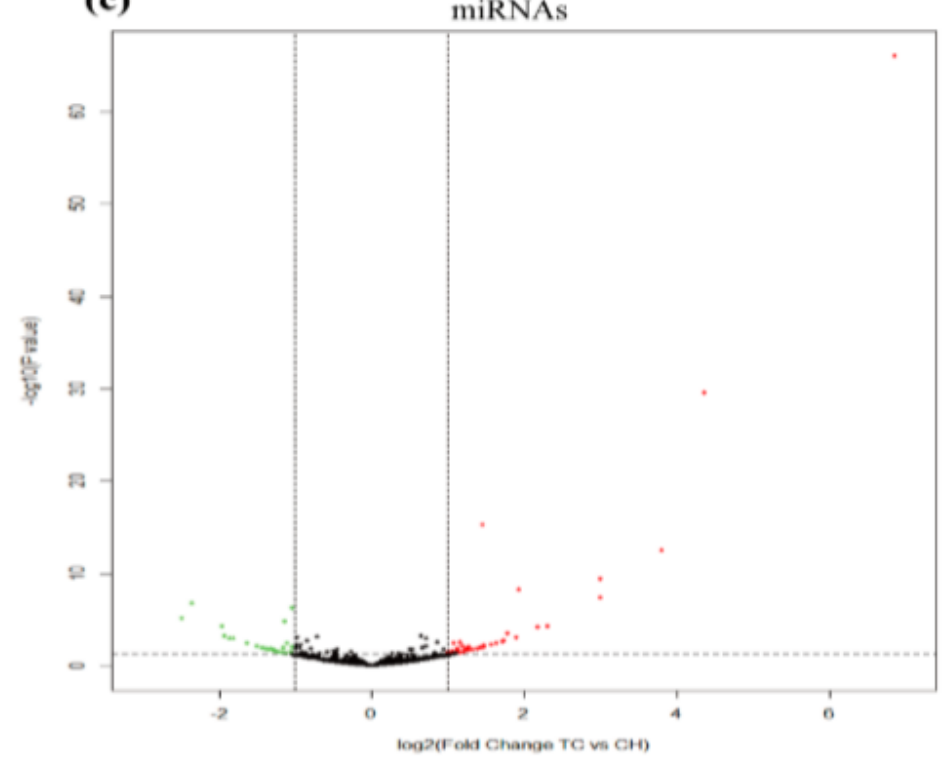

(b)
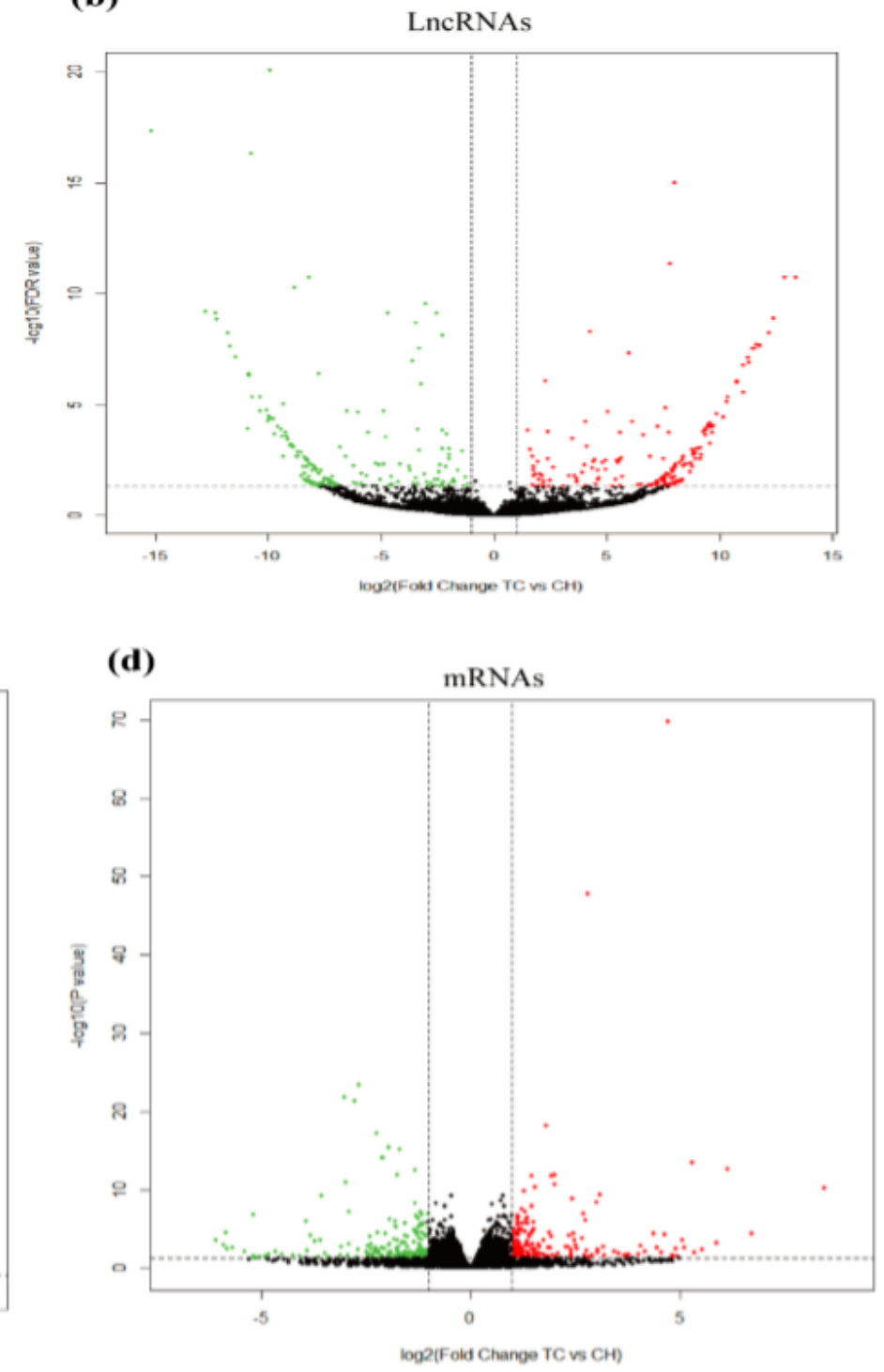

Figure 2

Identification of DELs, DEMs, and DEGs between TC and CH. Number of differentially expressed IncRNAs, miRNAs, and genes (a); Volcano plot displaying DELs (b), DEMs (c), and DEGs (d) between TC and CH. Upregulated and downregulated genes are shown in red and blue, respectively. Black dots represent genes with similar expression levels. 
(a)

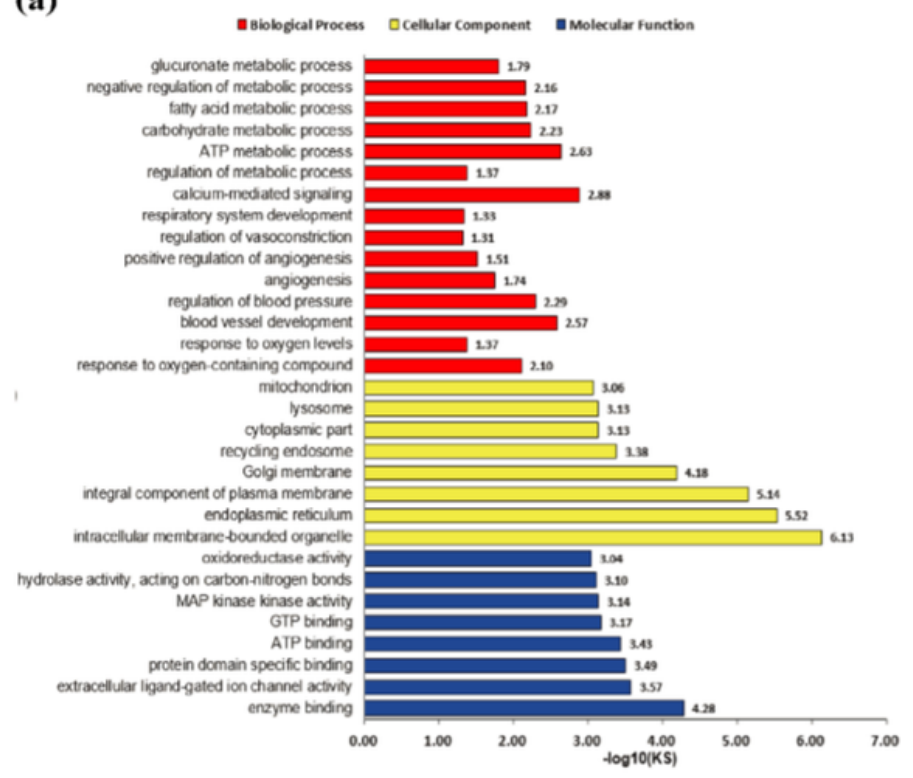

(c)

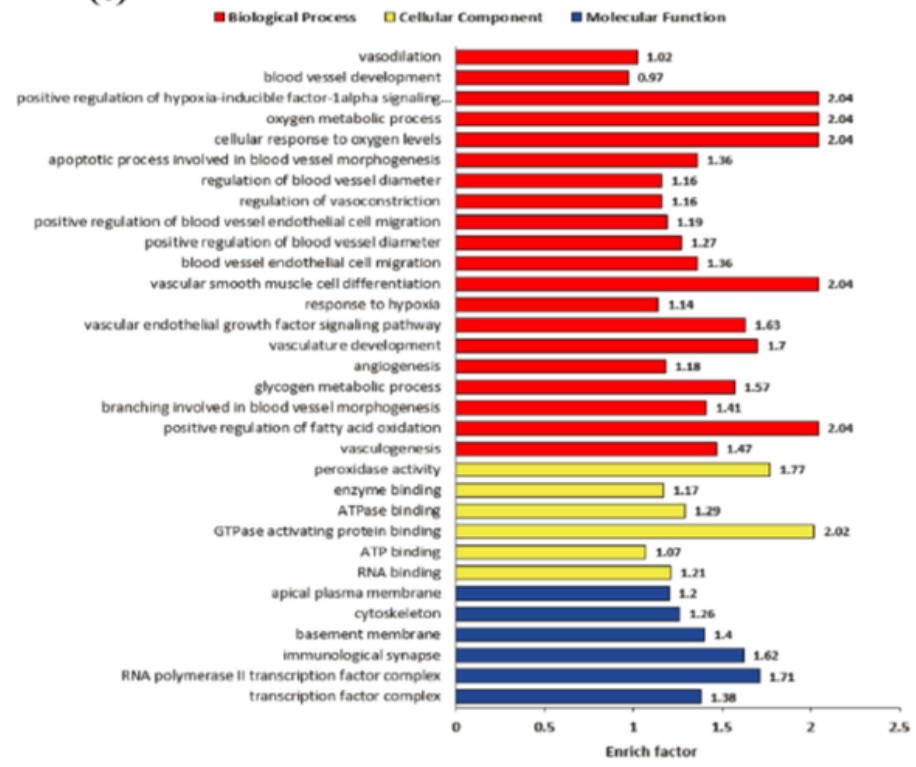

(b)

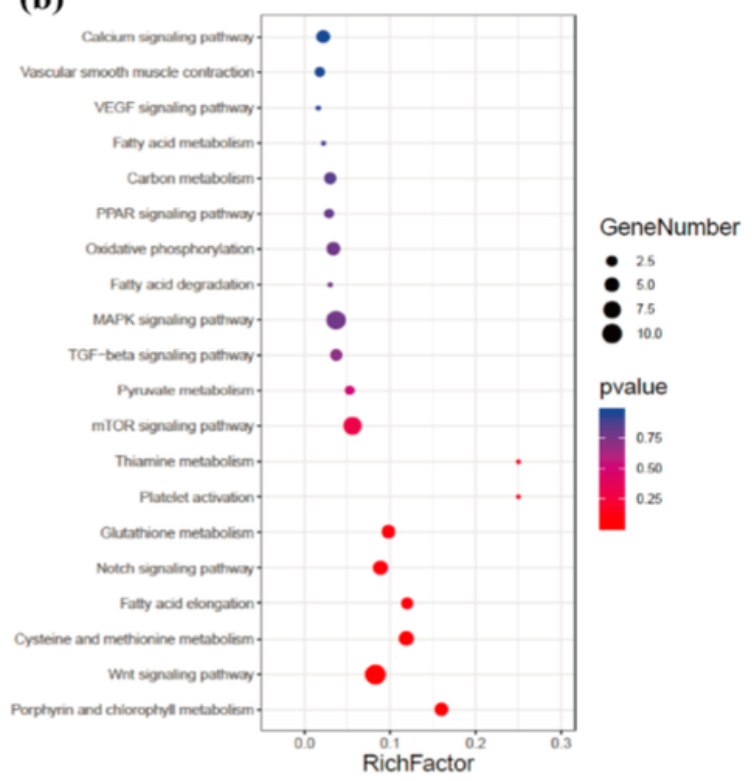

(d)

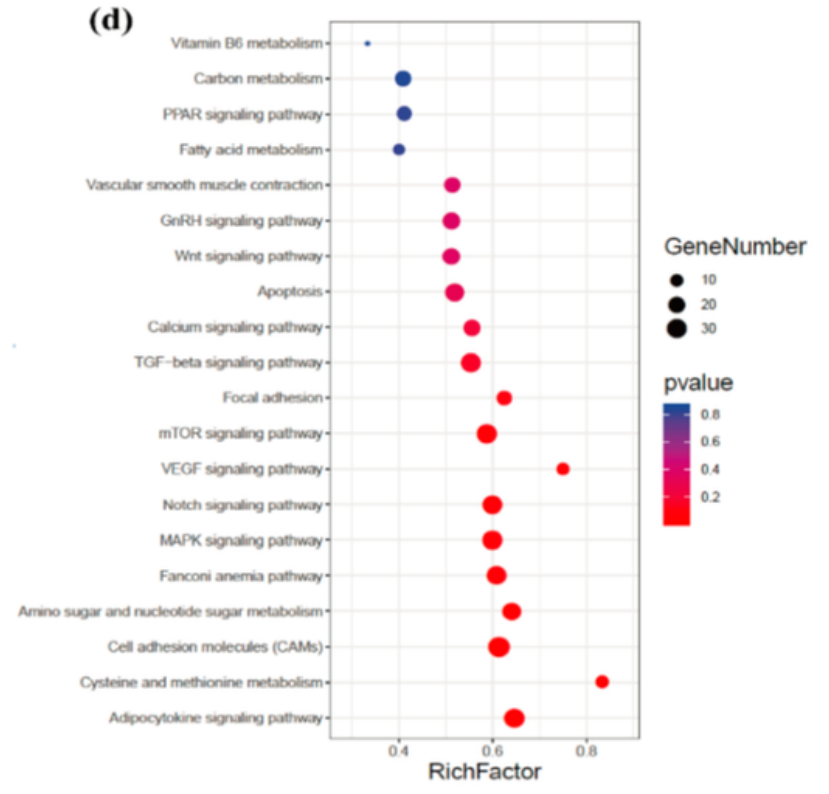

\section{Figure 3}

Functional analysis of DELs and DEMs. GO enrichment analysis of DELs (a) and DEMs (c) between TC and CH. KEGG enrichment analysis scatter plot of DELs (b) and DEMs (d) between $\mathrm{TC}$ and $\mathrm{CH}$; the rich factor is the ratio of DEL/DEM numbers annotated in the pathway term to the total gene numbers annotated in this pathway term. Smaller P-values indicate higher significance. TC, Tibetan chicken; $\mathrm{CH}$, Chahua chicken. 
(a)

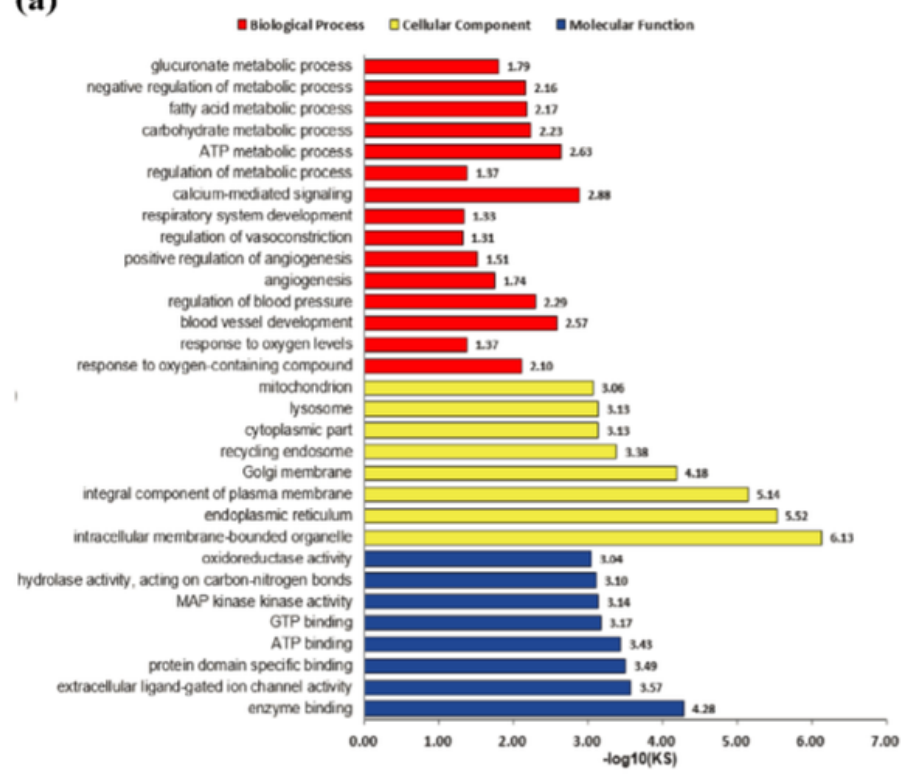

(c)

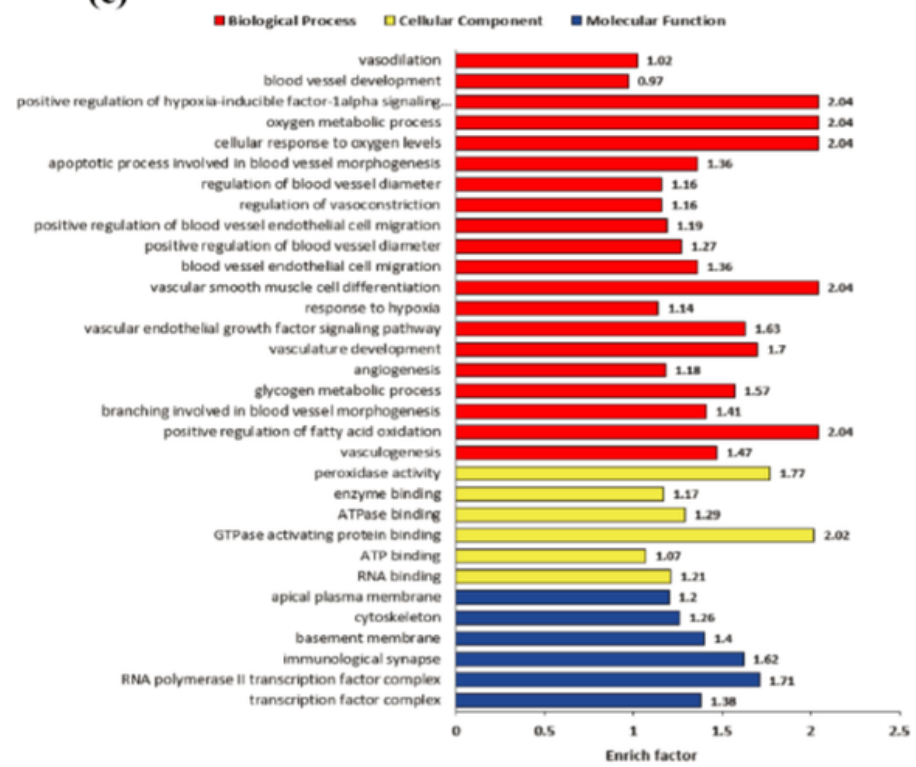

(b)

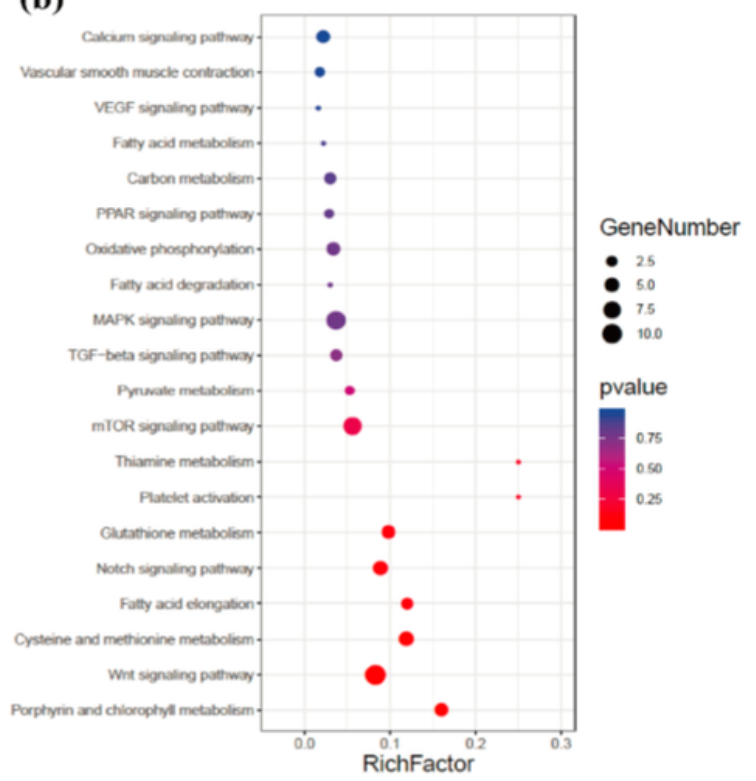

(d)

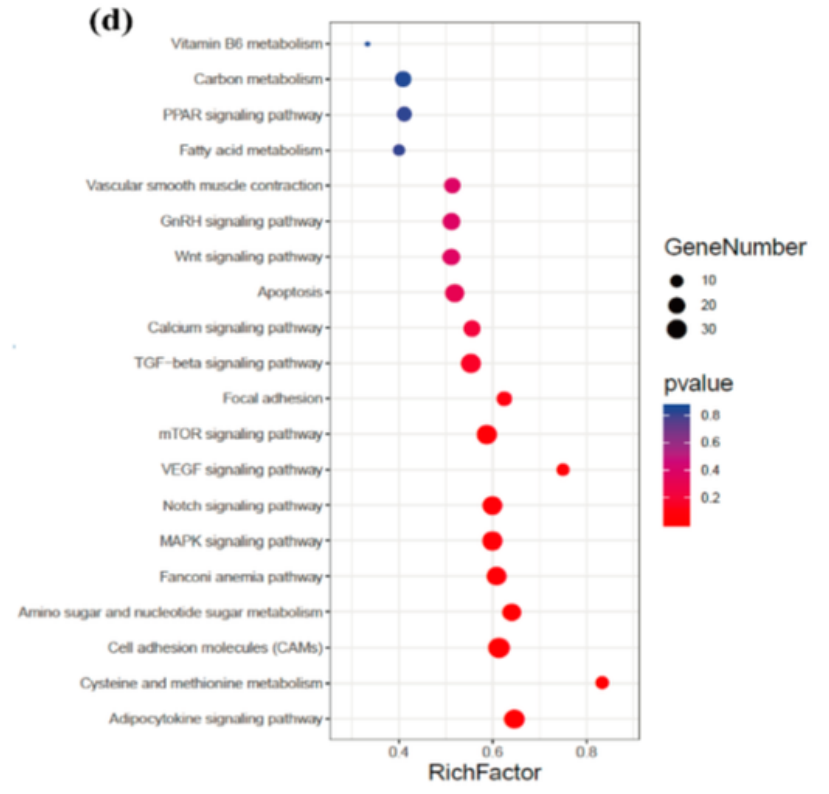

\section{Figure 3}

Functional analysis of DELs and DEMs. GO enrichment analysis of DELs (a) and DEMs (c) between TC and CH. KEGG enrichment analysis scatter plot of DELs (b) and DEMs (d) between $\mathrm{TC}$ and $\mathrm{CH}$; the rich factor is the ratio of DEL/DEM numbers annotated in the pathway term to the total gene numbers annotated in this pathway term. Smaller P-values indicate higher significance. TC, Tibetan chicken; $\mathrm{CH}$, Chahua chicken. 

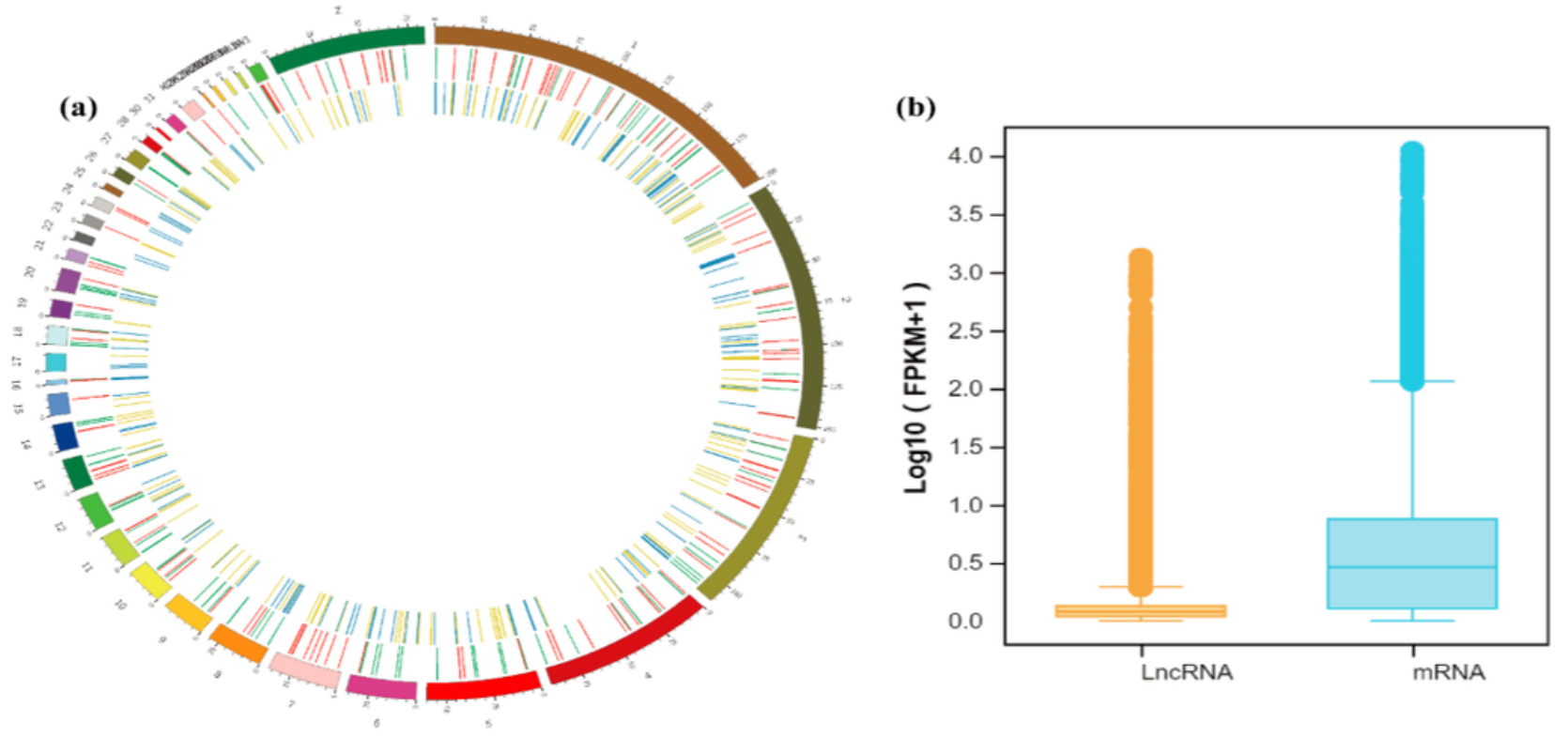

(c)

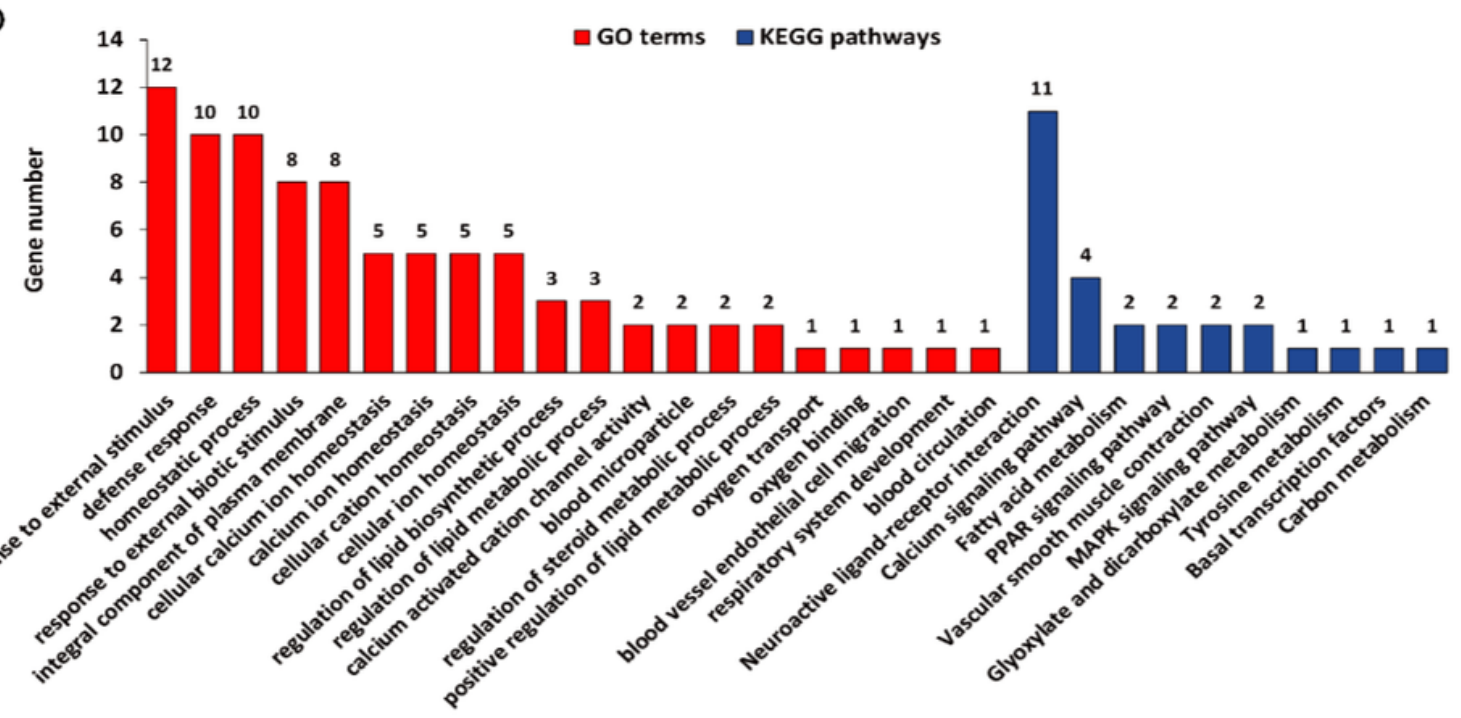

Figure 4

Comparative parsing of IncRNAs and mRNAs and functional analysis of DEGs. (a) Distribution of the expression of IncRNAs and mRNAs on the different chromosomes; (b) A comparison of expression between IncRNAs and mRNAs. The box chart statistics from top to bottom are the maximum value, upper quartile, middle value, lower quartile, and the minimum value; (c) GO and KEGG enrichment analysis of DEGs between TC and CH. TC, Tibetan chicken; $\mathrm{CH}$, Chahua chicken. 

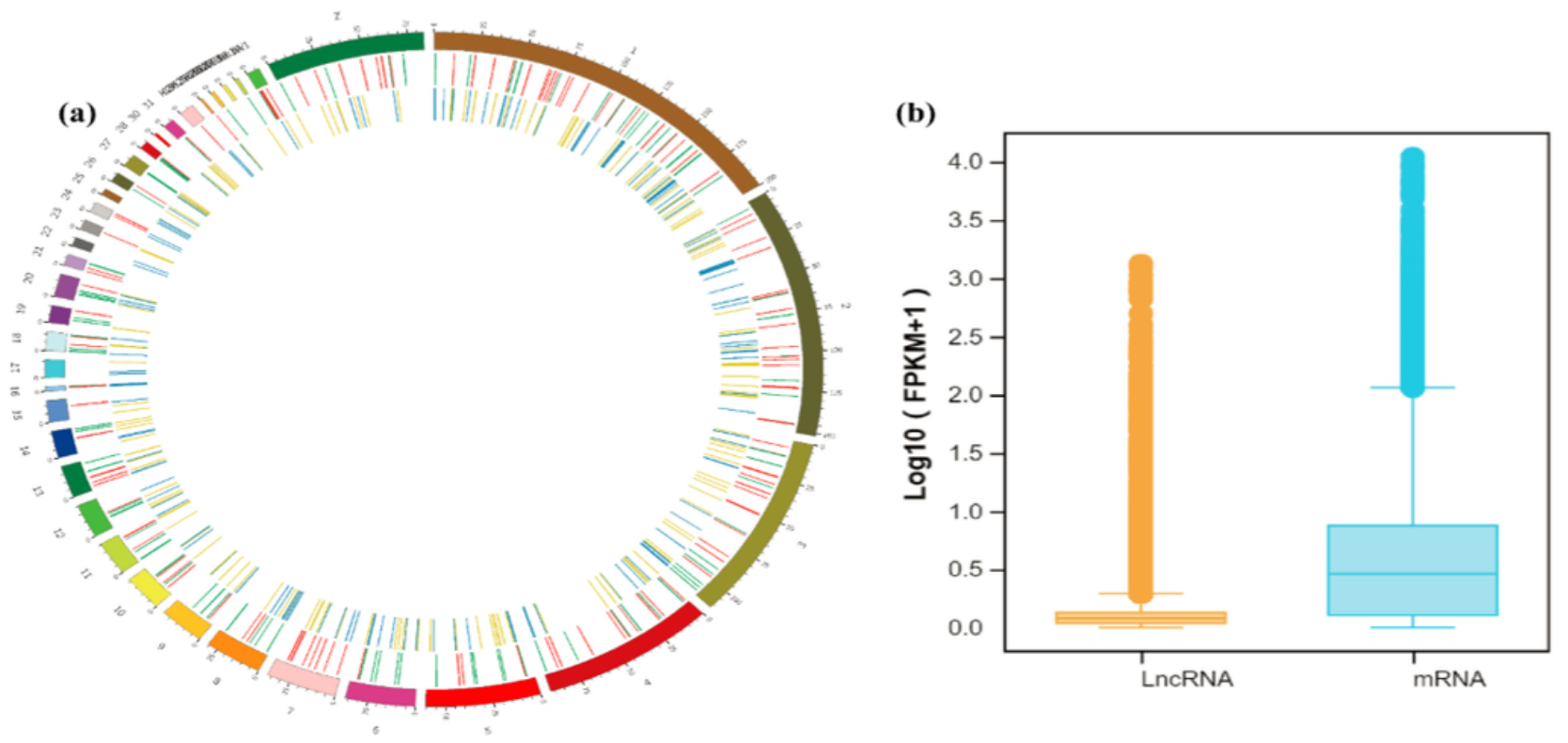

(c)

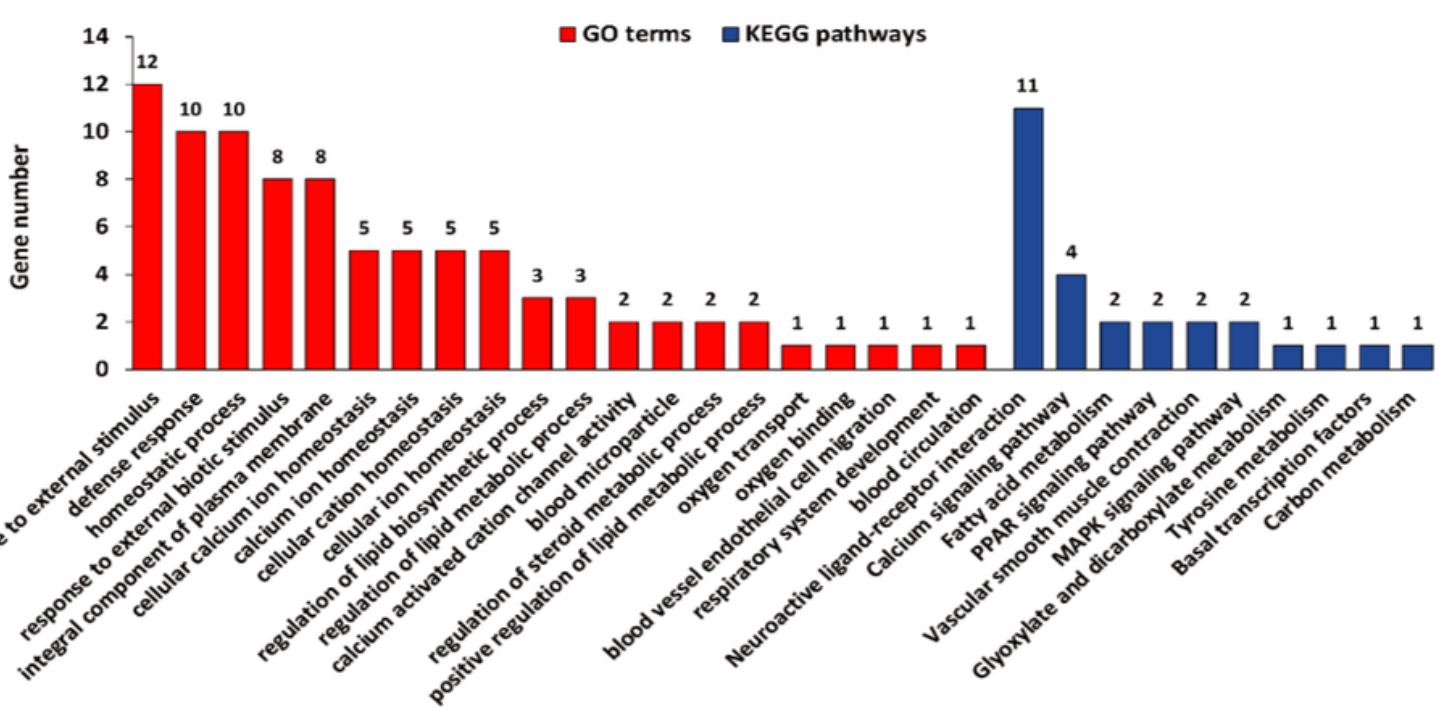

Figure 4

Comparative parsing of IncRNAs and mRNAs and functional analysis of DEGs. (a) Distribution of the expression of IncRNAs and mRNAs on the different chromosomes; (b) A comparison of expression between IncRNAs and mRNAs. The box chart statistics from top to bottom are the maximum value, upper quartile, middle value, lower quartile, and the minimum value; (c) GO and KEGG enrichment analysis of DEGs between TC and CH. TC, Tibetan chicken; $\mathrm{CH}$, Chahua chicken. 
(a)
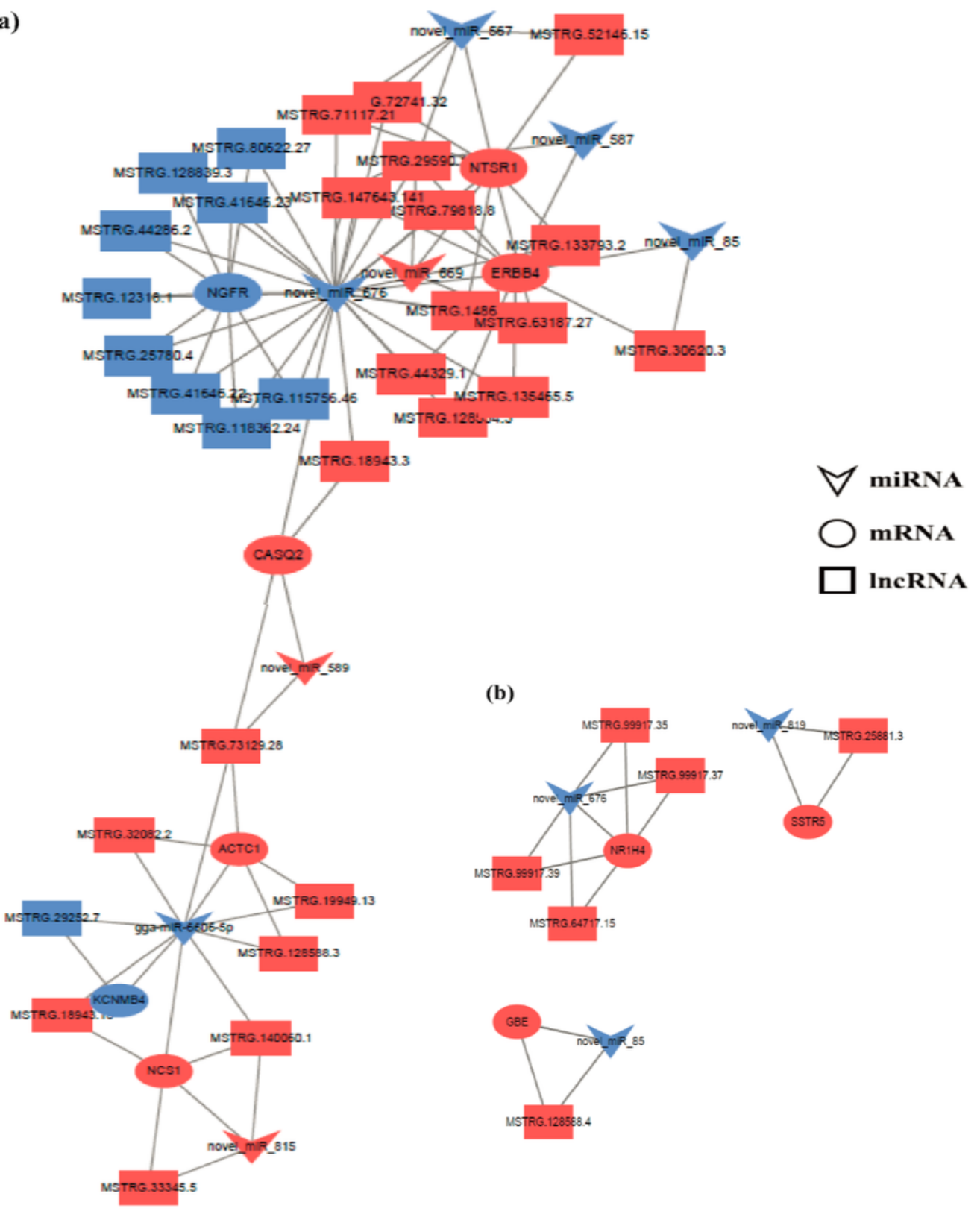

\section{Figure 5}

Mini-ceRNA network constructed with 10 DEGs and their 37 target DELs and 9 target DEMs, involved in angiogenesis (a) and energy metabolism (b). Color represents the up-regulated (red color) and down-regulated (blue color) levels. 
(a)
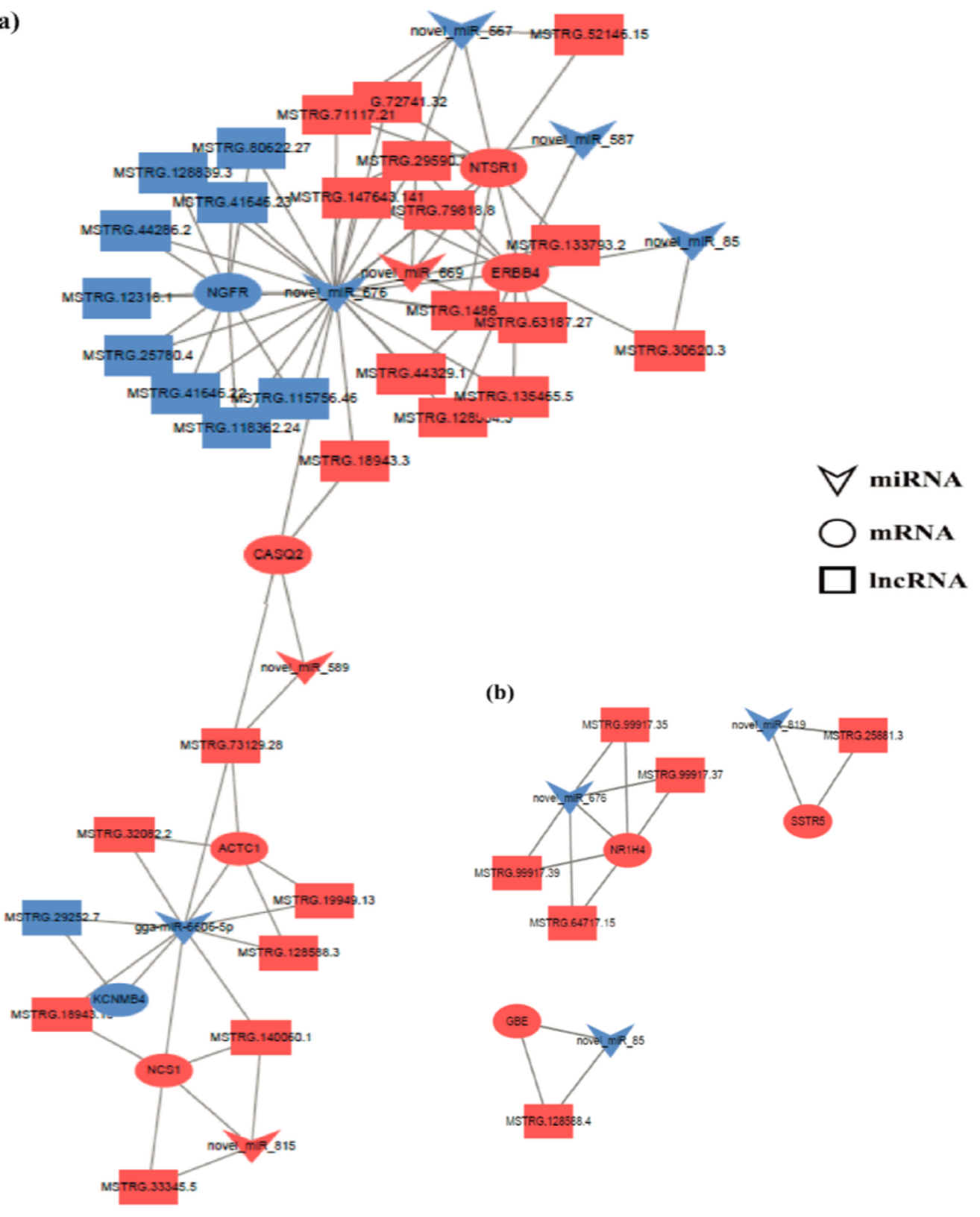

\section{Figure 5}

Mini-ceRNA network constructed with 10 DEGs and their 37 target DELs and 9 target DEMs, involved in angiogenesis (a) and energy metabolism (b). Color represents the up-regulated (red color) and down-regulated (blue color) levels. 


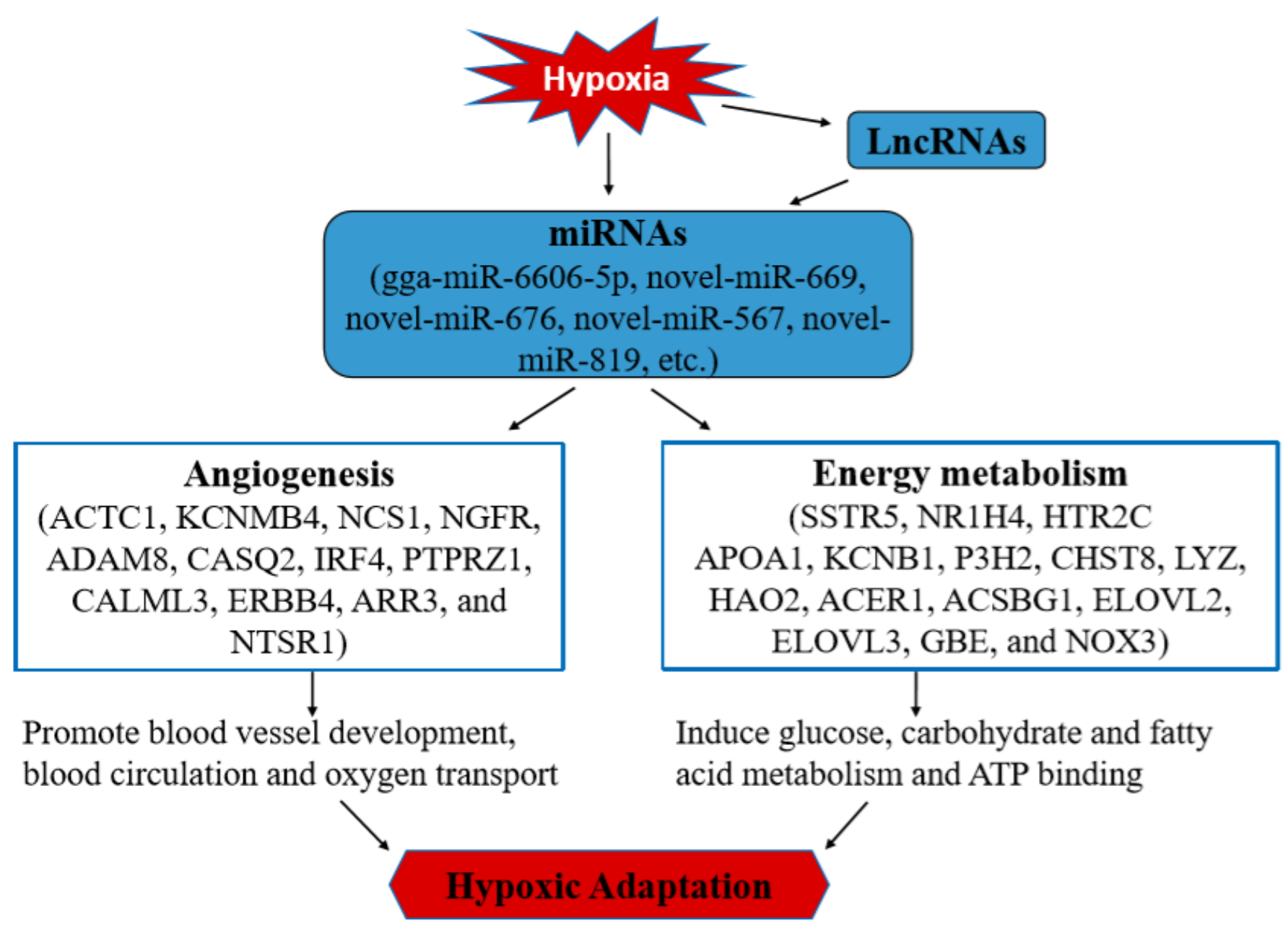

Figure 6

The expression of 6 DELs (a), 6 DEMs (c) and 7 DEGs (e) validated by qRT-PCR in chicken embryo chorioallantoic membrane (CAM) tissue. Note: The vertical axis represents the expression value of RNA in chicken embryo CAM and the horizontal axis represents names of RNAs. Error bars represent SE of expression. * on the bars indicate significant differences $(P<0.05)$ and ** indicate extremely significant differences $(P<0.01)$ between TC and CH breeds. TC = Tibetan chicken $(n=8) . C H=$ Chahua chicken $(n=8)$. The fold changes of the 6 DELs $(b), 6$ DEMs $(d)$ and 7 DEGs (f) showed that RT-qPCR results were consistent with the RNA-seq data. 


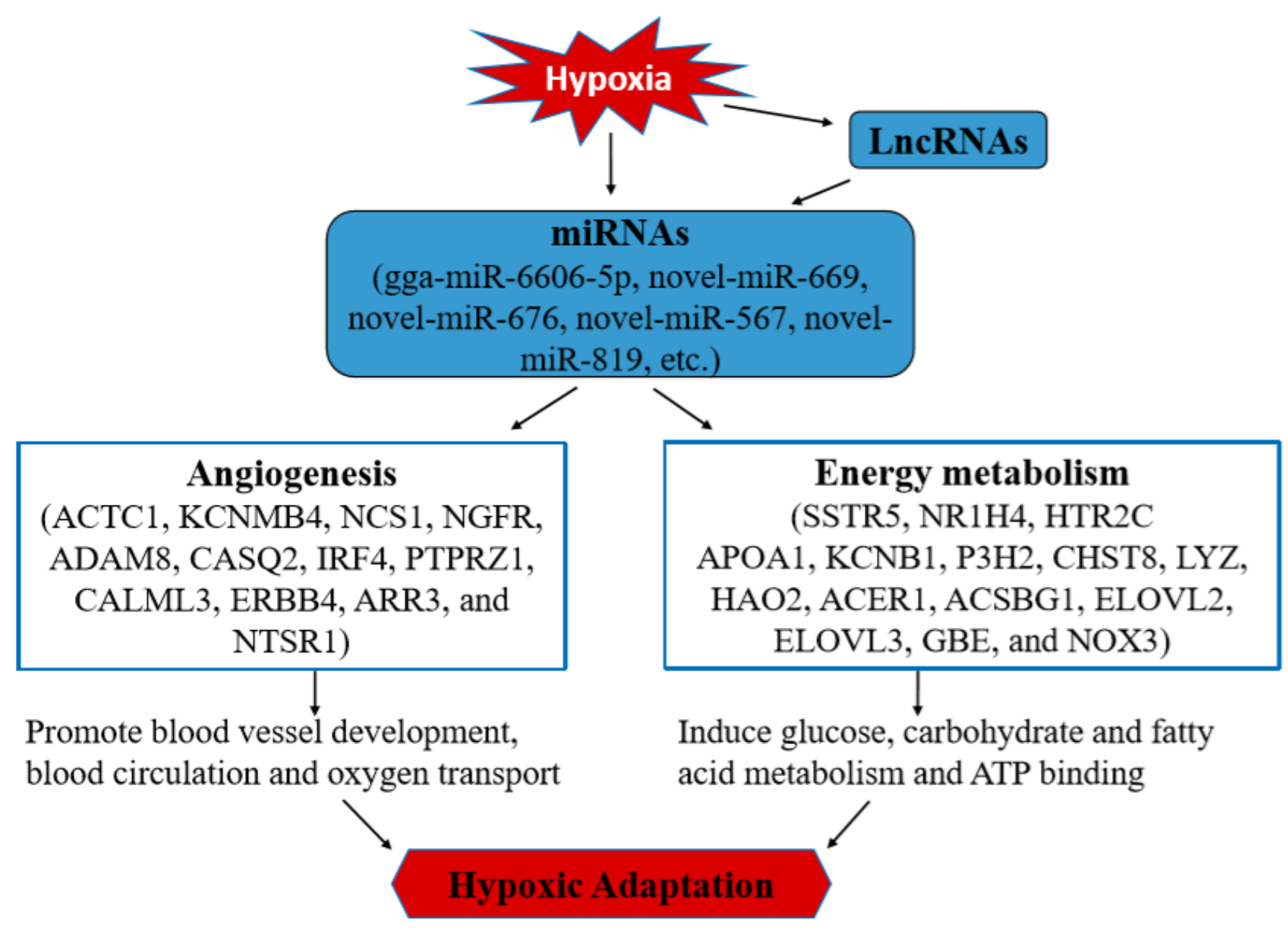

Figure 6

The expression of 6 DELs (a), 6 DEMs (c) and 7 DEGs (e) validated by qRT-PCR in chicken embryo chorioallantoic membrane (CAM) tissue. Note: The vertical axis represents the expression value of RNA in chicken embryo CAM and the horizontal axis represents names of RNAs. Error bars represent SE of expression. * on the bars indicate significant differences $(P<0.05)$ and ** indicate extremely significant differences $(P<0.01)$ between TC and CH breeds. TC = Tibetan chicken $(n=8) . C H=$ Chahua chicken $(n=8)$. The fold changes of the 6 DELs $(b), 6$ DEMs $(d)$ and 7 DEGs (f) showed that RT-qPCR results were consistent with the RNA-seq data. 

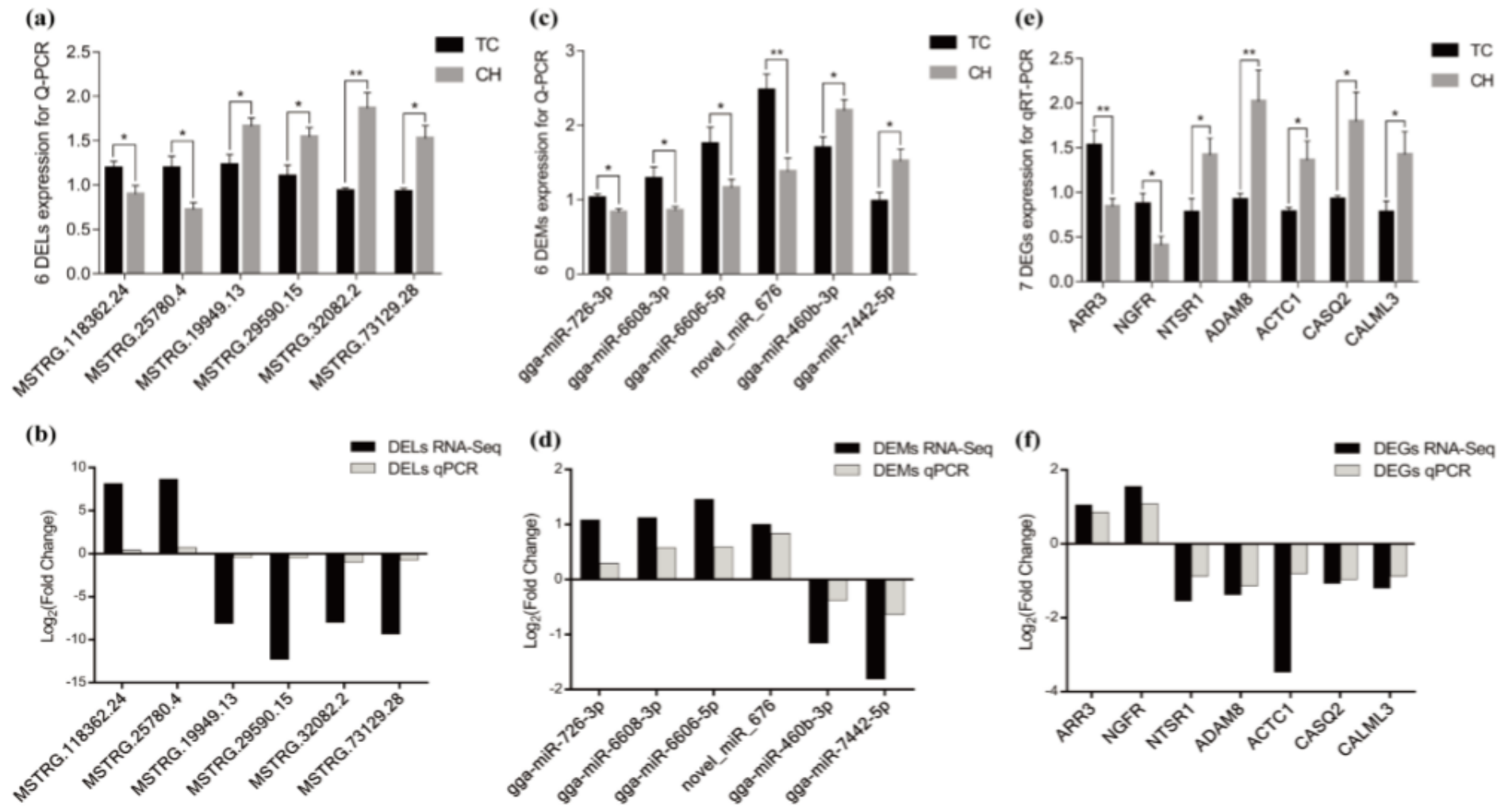

Figure 7

The proposed model of hypoxic adaptation in Tibetan chicken embryos. Under hypoxic conditions, miRNAs act as key regulators that directly target important DEGs. In this process, some IncRNAs can act as ceRNAs to competitively bind the MRE of miRNAs, indirectly affecting the expression of mRNAs.

(a)
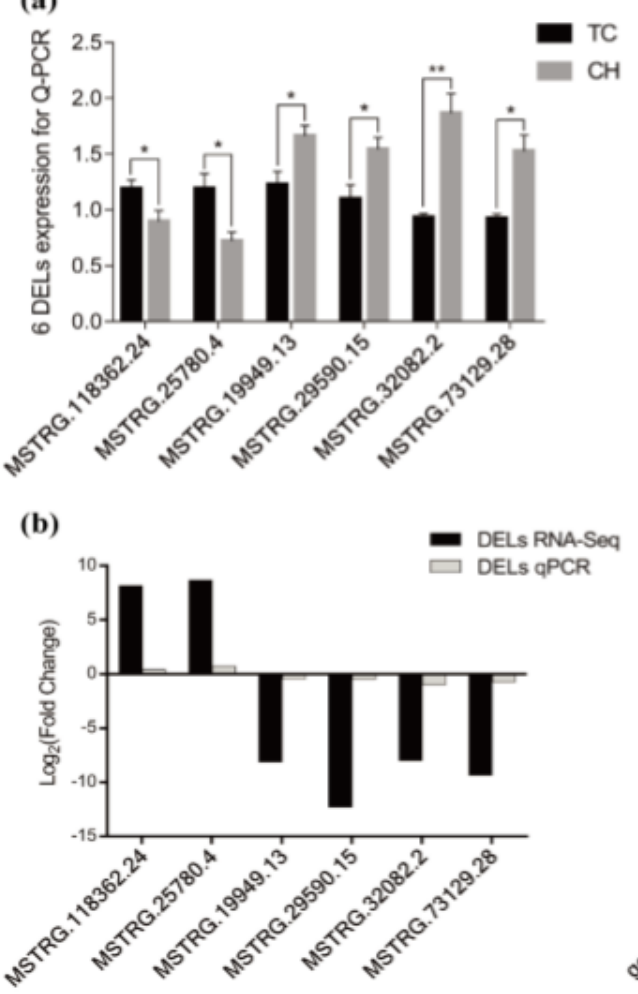

(c)
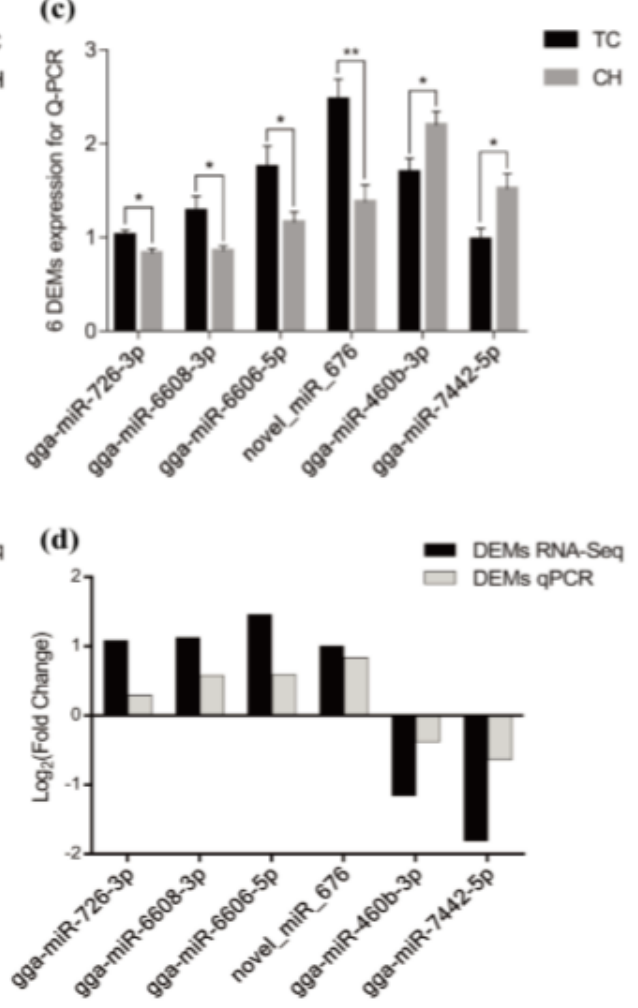

(e)
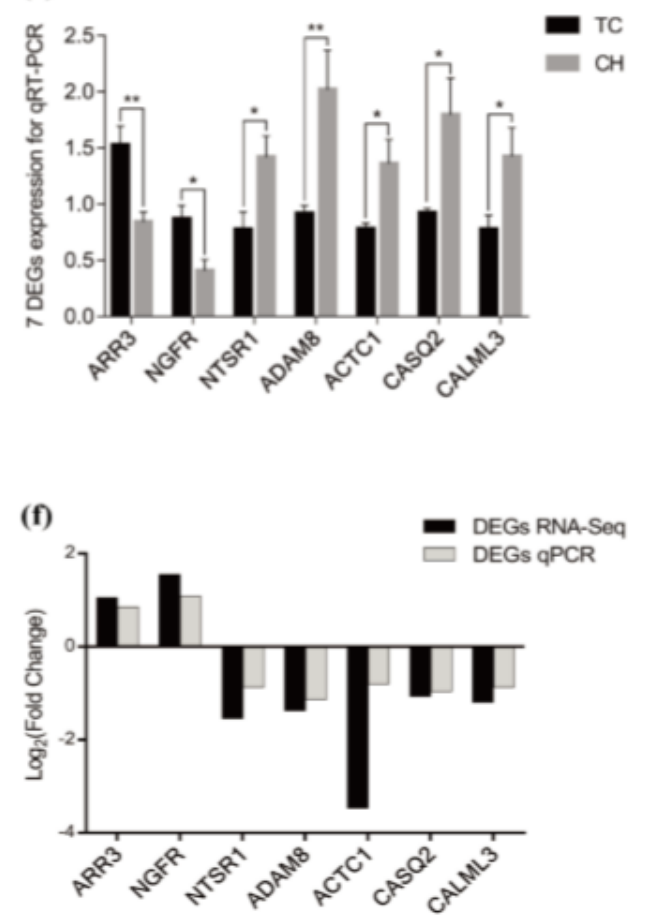


\section{Figure 7}

The proposed model of hypoxic adaptation in Tibetan chicken embryos. Under hypoxic conditions, miRNAs act as key regulators that directly target important DEGs. In this process, some IncRNAs can act as ceRNAs to competitively bind the MRE of miRNAs, indirectly affecting the expression of mRNAs.

\section{Supplementary Files}

This is a list of supplementary files associated with this preprint. Click to download.

- Additionalfile1TableS1.xlsx

- Additionalfile1TableS1.xlsx

- Additionalfile2Tables2.xIsx

- Additionalfile2Tables2.xlsx

- Additionalfile3Fig.S1S4.pdf

- Additionalfile3Fig.S1S4.pdf

- Additionalfile4TableS3.xlsx

- Additionalfile4TableS3.xlsx

- Additionalfile5TableS4.xIsx

- Additionalfile5Tables4.xlsx

- Additionalfile6Tables5.xlsx

- Additionalfile6TableS5.xIsx

- Additionalfile7TableS6.xlsx

- Additionalfile7TableS6.xlsx

- Additionalfile8TableS7.xlsx

- Additionalfile8TableS7.xlsx

- Additionalfile9Tables8.xIsx

- Additionalfile9Tables8.xlsx 